\title{
Testing Financing Constraints on Firm Investment using Variable Capital* $^{*}$
}

\author{
Andrea Caggese \\ Pompeu Fabra University
}

First version: February 2003

This version: August 2006

\begin{abstract}
We consider a dynamic multifactor model of investment with financing imperfections, adjustment costs and fixed and variable capital. We use the model to derive a test of financing constraints based on a reduced form variable capital equation. Simulation results show that this test correctly identifies financially constrained firms even when the estimation of firms' investment opportunities is very noisy. In addition, the test is well specified in the presence of both concave and convex adjustment costs of fixed capital. We confirm empirically the validity of this test on a sample of small Italian manufacturing companies.

JEL classification: D21, G31

Keywords: Financing Constraints, Investment
\end{abstract}

*I am most grateful to Nobu Kiyotaki for his encouragement and valuable feedback on my research. I would like also to thank Orazio Attanasio, Steven Bond, Martin Browning, Vicente Cunat, Christian Haefke, Francois Ortalo-Magne, Steve Pischke and the anonymous Referee for their valuable comments and suggestions on earlier versions of this paper, as well as the participants at the 2005 ASSA meetings in Philadelphia, the 2003 ESEM Congress in Stockholm, the 2003 CEPR Conference on Entrepreneurship, Financial Markets and Innovation, and at seminars at UPF, LSE, Banco de España, University of Copenhagen and Ente Einaudi. All errors are, of course, my own responsibility. Research support from the Financial Markets Group and from Mediocredito Centrale are gratefully acknowledged. Please address all correspondence to: andrea.caggese@upf.edu or Pompeu Fabra University, Department of Economics, Room 1E58, Calle Ramon Trias Fargas 25-27, 08005, Barcelona, Spain 


\section{Introduction}

In order to explain the aggregate behavior of investment and production, it is necessary to understand the factors that affect investment at firm level. Financing imperfections may prevent firms from accessing external finance and make them unable to invest unless internal finance is available. It is therefore important to study the extent to which financing constraints matter for firms' investment decisions. This line of inquiry is also relevant for other areas of research, such as the literature on the role of internal capital markets and banks, as well as the macro literature on the financial accelerator.

Starting with Fazzari, Hubbard and Petersen (1988), several studies investigate the presence of financing constraints by estimating the $Q$ model of investment with cash flow included as an explanatory variable. ${ }^{1}$ They argue informally that under certain conditions, and in the absence of financing frictions, Tobin's average $Q$ is equal to marginal $q$, and is a sufficient statistic for firm investment (Hayashi, 1982). It follows that, conditional on $Q$, cash flow should affect only the investment of financially constrained firms.

The motivation for this paper is that recent studies, starting with Kaplan and Zingales (1997 and 2000), have shown that the correlation between fixed investment and cash flow is not a good indicator of the intensity of firm financing constraints. In particular Erickson and Whited (2000) and Bond et al (2004) show that errors in measuring the expected profitability of firms explain most of the observed positive correlation between fixed investment and cash flow. Moreover, Gomes (2001), Pratap (2003) and Moyen (2004) simulate industries with heterogeneous firms who may face financing frictions. They show that the correlation between fixed investment and cash flow may be positive for financially unconstrained firms, and even larger than that of financially constrained firms. ${ }^{2}$ Finally, Caballero and Leahy (1996) show that the failure of the investment - cash flow correlation as a measure of financing constraints may be caused not only by the measurement error in $Q$, but also by misspecification and omitted variable problems.

The objective of this paper is to develop a new financing constraints test that is robust to

\footnotetext{
${ }^{1}$ See Hubbard (1998) for a review of this literature.

${ }^{2}$ Alti (2003) and Abel and Eberly (2003) and (2004) develop theoretical frameworks in which positive investment-cash flow correlations arise in the absence of financial markets imperfections.
} 
these problems and has the following properties: i) it is able to detect both the presence and the intensity of financing constraints on firm investment; ii) it is efficient even in the presence of large errors in the measurement of the productivity shock; iii) it is well specified under a wide range of assumptions concerning the adjustment costs of fixed capital.

The test is derived from a structural model of a risk-neutral firm that generates output using two complementary factors of production, fixed and variable capital. Fixed capital is irreversible, while variable capital can be adjusted without frictions. Because of an enforceability problem, the firm can obtain external financing only if it secures it with collateral. The assets of the firm can only be partially collateralizable and some down payment is needed to finance investment.

We describe the optimality conditions of the model and we demonstrate that under the hypothesis of financing imperfections, the correlation between financial wealth and variable capital investment is a reliable indicator of the presence of financing constraints. We use this result to develop a formal financing constraint test based on a reduced form variable investment equation. This new test has two main advantages with respect to the previous literature. First, variable investment is less influenced by adjustment costs than fixed investment. This property reduces misspecification and omitted variable problems in the investment equation, thereby making it easier to distinguish the contribution of financial factors from the contribution of productivity shocks to firms' investment decisions. Second, while fixed investment decisions are forward looking, variable investment decisions are mostly affected by the current productivity shock, which is relatively easy to estimate even if only balance sheet data are available. Therefore our financing constraints test does not require the estimation of Tobin's $Q$, and it can be applied also to small privately owned firms not quoted on the stock markets. This property of the test is important. The previous investment literature has mainly studied the financing constraints of large firms quoted on the stock markets, even tough financing frictions are mostly relevant for the financing of small privately owned firms. ${ }^{3}$ One reason for this bias is that the previous

\footnotetext{
${ }^{3}$ Among the exceptions, Himmelberg and Petersen (1994) and Whited (2006) consider data sets of publicly owned firms focusing explicitly on small and very small firms. Jaramillo, Schiantarelli, and Weiss (1996), Gelos and Werner (2002) and Lízal and Svejnar (2002) study samples of small privately owned firms in developing countries. However the claim that small firms do not matter for developed economies, because large firms account for most of the aggregate employment and output, is not correct. For example, in 1995, small firms with less than 100 employees accounted for $37.9 \%$ of the total employment in the US economy (source: US Census).
} 
literature focuses mostly on the $Q$ model, where average $Q$ is computed as the ratio of the market value of the firm / the replacement value of its assets. However, because the market value is easily measurable only for publicly traded firms, this approach precludes the analysis of the effects of financing constraints on privately owned firms. ${ }^{4}$

We study the properties of the new financing constraints test by solving the model and simulating several industries with heterogenous firms. We show that the sensitivity of variable capital to financial wealth is able to detect both the presence and the intensity of financing constraints on firm investment. This result is robust to both concave and convex adjustment costs of fixed capital. More importantly, large observational errors in measuring the productivity shock do not affect the power of the test, because the financial wealth of the simulated firms has a very low correlation with the current productivity shock.

We verify the validity of this test on two datasets of Italian manufacturing firms. These datasets are very useful for the purpose of this paper for two reasons: i) almost all of the firms considered are small and not quoted on the stock market; ii) all the firms are also covered by in-depth surveys with qualitative information about the financing problems the firms faced in funding investment.

We estimate the variable investment equation on these datasets and we confirm the predictions of the model. First, the estimated coefficients do not reject the restrictions imposed by the structural model. Second, the sensitivity of variable investment to internal finance is significantly positive for firms that are likely to face capital markets imperfections (according to the qualitative survey) while it is always very small and not significantly different from zero for the other firms.

This paper contributes to both the theoretical and empirical literature on financing constraints and firm investment. The simulation results of this paper are related to Gomes (2001), Pratap (2003) and Moyen (2004). Because we consider both convex and non-convex adjustment

\footnotetext{
${ }^{4}$ One can in principle use other methods to calculate marginal $q$ using only balance sheet data. For example Gilchrist and Himmelberg (1998) apply the VAR approach of Abel and Blanchard (1986) to a panel of firms. But probably the resulting estimate of marginal $q$ is even more noisy than the average $Q$ calculated using the stock market valuation of firms. Therefore the financing constraints test based on this measure of marginal $q$ is probably even less reliable than the test based on average $Q$.
} 
costs, we are able to clarify the relationship between adjustment costs and the investmentinternal finance relationship. In our benchmark model, fixed capital is irreversible and $q$ is not a sufficient statistic for investment. In this case, the cash flow - investment sensitivity is highest for financially unconstrained firms, even in the absence of measurement errors in $q$, as is also found by Moyen (2004). In the alternative model fixed capital is subject to convex adjustment costs and $q$ is a sufficient statistic for investment. We show that in this case, the cash flow - investment sensitivity is a reliable indicator of financing constraints, even in the presence of large measurement errors in $q$.

Because of its emphasis on the importance of adjustment costs to understand the investment decisions made by firms, this paper is related to Barnett and Sakellaris (1998) and to Abel and Eberly (2002), who analyze the implications of different types of adjustment costs on the relationship between marginal $Q$ and investment at the firm and at the aggregate level. Moreover it is related to Whited (2006) who shows that, in the presence of fixed costs of investment, constrained firms are less likely to undertake a new, large investment project than unconstrained firms, after controlling for expected productivity and for the time elapsed since the last large investment project.

The empirical section of this paper uses a structural model of firm investment to derive a financing constraints test that is based on a simple reduced form linear investment equation. A similar approach is followed by Hennessy, Levy and Whited (2006), who derive an enhanced version of the $Q$ model that allows for the presence of financing frictions and debt overhang. Carpenter and Petersen (2003) estimate a version of the $Q$ model with cash-flow where the dependent variable is the growth of total assets of the firm rather than the fixed investment rate.

Our method to test for financing constraints on firm investment can be applied using any reversible factor of production. This paper considers the usage of variable inputs as the dependent variable of the test. Therefore it is also related to Kashyap, Lamont and Stein (1994) and Carpenter, Fazzari and Petersen (1998). These authors show that inventories at firm level are very sensitive to internal finance, especially for those firms a priori more likely to be financially 
constrained. With respect to these authors, our paper, in addition to proposing a more rigorous financing constraints test that identifies both the presence and the intensity of financing constraints, has two further advantages. First, while the flow of the usage of materials is very close to a frictionless variable input, changes in total inventories are potentially subject to adjustment costs of various nature, such as the presence of fixed costs that imply $(\mathrm{S}, \mathrm{s})$ type of inventory policies. Therefore the reduced form linear inventory models estimated by Kashyap, Lamont and Stein (1994) and Carpenter, Fazzari and Petersen (1998) are potentially subject to misspecification problems, which make it difficult to distinguish whether internal finance significantly affects inventories because of financing frictions or because it is capturing other omitted information. Second, even if financing constraints affect inventory decisions, this does not necessarily imply that they also affect the investment in production inputs and the level of production of the firm. Indeed the very fact that a financially constrained firm can absorb a reduction in cash flow with a reduction in inventories means that it may be able to maintain the desired flow of variable inputs into the production process. Instead, the objective of this paper is precisely to estimate the intensity of financing constraints on the investment in variable inputs and on the production of the firm.

This paper is organized as follows: section II describes the model. Section III defines the new financing constraints test. Section IV illustrates the simulation results. Section V verifies the validity of the new financing constraints test using a balanced panel of Italian firms and finally, section VI summarizes the conclusions.

\section{The model}

The aim of this section is to develop a structural model of investment with financing constraints and with adjustment costs of fixed capital. We consider a risk-neutral firm whose objective is to maximize the discounted sum of future expected dividends. The discount factor is equal to $1 / R$, where $R=1+r$, and $r$ is the lending/borrowing risk-free interest rate.

The firm operates with two inputs, $k_{t}$ and $l_{t}$, fixed and variable capital respectively. The production function is strictly concave in both factors. We assume a Cobb-Douglas functional 
form:

$$
y_{t}=\theta_{t} k_{t}^{\alpha} l_{t}^{\beta} \text { with } \alpha+\beta<1 .
$$

All prices are constant and normalized to 1. This simplifying assumption will be relaxed in the empirical section of the paper. $\theta_{t}$ is a productivity shock that follows a stationary AR(1) stochastic process. For simplicity we assume that variable capital is nondurable and fully depreciates after one period, while fixed capital is durable:

$$
0<\delta<1
$$

in which $\delta$ is the depreciation rate of fixed capital. Moreover variable capital investment is not subject to adjustment costs, while fixed capital investment is irreversible:

$$
i_{t+1} \geq 0,
$$

in which $i_{t+1}$ is gross fixed investment:

$$
i_{t+1} \equiv k_{t+1}-(1-\delta) k_{t}
$$

We assume full irreversibility for convenience, but the results of the paper would also hold for other types of non-convex adjustment costs, such as partial irreversibility or fixed costs. Moreover in section IV we relax this assumption allowing also for convex adjustment costs.

Financial imperfections are introduced by assuming that new share issues and risky debt are not available. At time $t$ the firm can borrow from (and lend to) the banks one period debt, with face value $b_{t+1}$, at the market riskless interest rate $r$. A positive (negative) $b_{t+1}$ indicates that the firm is a net borrower (lender). Banks only lend secured debt, and the only collateral they accept is physical capital. Therefore at time $t$ the borrowing capacity of the firm is limited by the following constraints:

$$
b_{t+1} \leq v k_{t+1}
$$

$$
d_{t} \geq 0
$$




$$
0<v \leq 1-\delta
$$

$d_{t}$ are dividends. $v$ is the share of fixed capital that can be used as collateral. One possible justification for constraint (5) is that the firm can hide the revenues from production. Being unable to observe such revenues, the banks can only claim the residual value of the firm's physical assets as repayment of the debt (Hart and Moore, 1998). ${ }^{5}$ If $v=1-\delta$ then all the residual value of fixed capital is accepted as collateral. This is possible because we assume that the irreversibility constraint (3) does not apply when the firm as a whole is liquidated and all its assets are sold. ${ }^{6}$

The timing of the model is as follows: new capital purchased in period $t-1$ generates output in period $t$. At the beginning of period $t$ the firm's technology becomes useless with an exogenous probability $1-\gamma$. In this case the assets of the firm are sold and the revenues are distributed as dividends. Instead with probability $\gamma$ the firm continues activity. Then $\theta_{t}$ is realized, $y_{t}$ is produced using $k_{t}$ and $l_{t}$, the production inputs purchased in the previous period, and $b_{t}$ is repaid. The exogenous exit probability is necessary in order to generate simulated industries in which a fraction of firms are financially constrained in equilibrium. If $\gamma=1$ and firms live forever then they eventually accumulate enough wealth to become unconstrained, and the simulated industry always converges to a stationary distribution of financially unconstrained firms, no matter how tight the financing constraint (5) is.

It is useful to define the net worth of the firm $w_{t}$, after the debt $b_{t}$ is repaid, as follows:

$$
w_{t}=w_{t}^{F}+(1-\delta) k_{t}
$$

Where $w_{t}^{F}$ is financial wealth:

$$
w_{t}^{F}=y_{t}-b_{t}
$$

\footnotetext{
${ }^{5}$ Some authors argue that variable capital has a higher collateral value than fixed capital (Berger et al, 1996). Nevertheless the results derived in this section are consistent with alternative specifications that allow for a positive collateral value of variable capital.

${ }^{6}$ In theory, the interactions between financing constraints and adjustment costs of fixed capital may imply that in some cases the firm is forced to liquidate the activity to repay the debt, even if it would be profitable to continue. In order to simplify the analysis, we focus in this paper on the set of parameters that do not allow this outcome to happen in equilibrium.
} 
After producing, the firm allocates $w_{t}^{F}$ plus the new borrowing between dividends, fixed capital investment and variable capital investment, according to the following budget constraint:

$$
d_{t}+l_{t+1}+i_{t+1}=w_{t}^{F}+b_{t+1} / R
$$

For convenience, we define $a_{t}$ as the stock of financial savings:

$$
a_{t} \equiv-b_{t}
$$

We define $a^{*}$ as the minimum level of financial savings such that the borrowing constraint (5) is never binding for every period $j \geq t$. The concavity of the production function (1) and the stationarity of the productivity shock $\theta$ ensure that $a^{*}$ is positive and finite. Intuitively, when $a_{t} \geq a^{*}$ the returns from savings are always higher than the maximum losses from the production activity: $r a_{t}^{*}>\max _{k_{t}, \theta_{t}}\left(l_{t+1}+i_{t}-y_{t}\right)$. Because the discount factor of the firm is equal to $1 / R$, when $a_{t}<a^{*}$ the firm faces future expected financing constraints and always prefers to retain rather than to distribute earnings. Instead when $a_{t} \geq a^{*}$ the firm is indifferent between retaining and distributing net profits. Therefore we make the following assumption:

Assumption 1: if $a_{t} \geq a^{*}$ then the firm distributes net profits as dividends:

$$
d_{t}=y_{t}-l_{t+1}-i_{t+1}+r a_{t} \text { if } a_{t} \geq a_{t}^{*}
$$

Equation (10) implies that the firm distributes as dividends the extra savings above $a^{*}$. Assumption 1 is only necessary to provide a natural upper bound to the value of $w_{t}^{F}$, and it does not affect the real investment decisions of the firm.

Let's denote the value at time $t$ of the firm, after $\theta_{t}$ is realized, by $V_{t}\left(w_{t}, \theta_{t}, k_{t}\right)$ :

$$
\begin{aligned}
& V_{t}\left(w_{t}, \theta_{t}, k_{t}\right)=\underset{k_{t+1}, l_{t+1}, b_{t+1}}{M A X} \pi_{t}+\frac{\gamma}{R} E_{t}\left[V_{t+1}\left(w_{t+1}, \theta_{t+1}, k_{t+1}\right)\right] \\
& \pi_{t}=\gamma d_{t}+(1-\gamma) w_{t}
\end{aligned}
$$

The firm maximizes (11) subject to equations (5), (6) and (9). Appendix 1 provides a proof that the optimal policy functions $k_{t+1}\left(w_{t}, \theta_{t}, k_{t}\right), l_{t+1}\left(w_{t}, \theta_{t}, k_{t}\right)$ and $b_{t+1}\left(w_{t}, \theta_{t}, k_{t}\right)$ exist and are unique. 
In order to describe the optimality conditions of the model, we use equation (9) to substitute $d_{t}$ in the value function (11). Let $\mu_{t}, \lambda_{t}$ and $\phi_{t}$ be the Lagrangian multipliers associated respectively with the irreversibility constraint (3), the borrowing constraint (5) and the non-negativity constraint on dividends (6). The solution of the problem is defined by the following conditions:

$$
\begin{gathered}
\phi_{t}=R \lambda_{t}+\gamma E_{t}\left(\phi_{t+1}\right) \\
E_{t}\left(\frac{\partial y_{t+1}}{\partial k_{t+1}}\right)=\left\{R\left[1+E_{t}\left(\Psi_{t+1}^{k}\right)\right]-(1-\delta)\right\}-R \mu_{t}+\Phi_{t} E_{t}\left(\mu_{t+1}\right) \\
E_{t}\left(\frac{\partial y_{t+1}}{\partial l_{t+1}}\right)=R\left[1+E_{t}\left(\Psi_{t+1}^{l}\right)\right] \\
\left(1-\frac{\tau_{k}}{R}\right) k_{t+1}+l_{t+1} \leq w_{t}^{F}+(1-\delta) k_{t}-d_{t}
\end{gathered}
$$

Where:

$$
\begin{aligned}
\Phi_{t} & =\frac{\gamma\left(1-\delta_{k}\right)}{1+\gamma E_{t}\left(\phi_{t+1}\right)} \\
E_{t}\left(\Psi_{t+1}^{k}\right) & =\frac{\left(R-\tau_{k}\right) \lambda_{t}-\frac{\gamma}{R} \operatorname{cov}\left(\phi_{t+1}, \frac{\partial y_{t+1}}{\partial k_{t+1}}\right)}{1+\gamma E_{t}\left(\phi_{t+1}\right)} \\
E_{t}\left(\Psi_{t+1}^{l}\right) & =\frac{R \lambda_{t}-\frac{\gamma}{R} \operatorname{cov}\left(\phi_{t+1}, \frac{\partial y_{t+1}}{\partial l_{t+1}}\right)}{1+\gamma E_{t}\left(\phi_{t+1}\right)}
\end{aligned}
$$

Equations (13), (14) and (15) are the first order conditions of $b_{t+1}, l_{t+1}$ and $k_{t+1}$ respectively. Equation (16) combines the budget constraint (9) and the collateral constraint (5) and implies that the down payment necessary to buy $k_{t+1}$ and $l_{t+1}$ must be lower than the residual net worth after paying the dividends. By iterating forward equation (13) we obtain:

$$
\phi_{t}=R \sum_{j=0}^{\infty} E_{t}\left(\lambda_{t+j}\right)
$$

Equation (20) implies that as long as there are some current or future expected financing constraints, then $\phi_{t}>0$ and the firm does not distribute dividends: $d_{t}=0$. Equation (14) represents the optimality condition for the fixed capital $k_{t+1}$. The left-hand side is the marginal productivity of fixed capital and the right-hand side the marginal cost of fixed capital. The term 
$\left\{R\left[1+E_{t}\left(\Psi_{t+1}^{k}\right)\right]-(1-\delta)\right\}$ is the shadow cost of buying one additional unit of fixed capital net of its residual value $(1-\delta)$. The term $E_{t}\left(\Psi_{t+1}^{k}\right)$ is equal to zero if the firm is not financially constrained today or in the future. The term $\mu_{t}$ measures the shadow cost of a currently binding irreversibility constraint. Future expected irreversibility constraints $E_{t}\left(\mu_{t+1}\right)$ are multiplied by the term $\Phi_{t}$, which is an increasing function of the expected shadow value of money $1+E\left(\phi_{t+1}\right)$. Therefore the more the firm expects to be financially constrained in the future, the higher the cost of future expected irreversibility constraints. Equation (15) is the optimality condition for the variable capital $l_{t+1}$. The term $E_{t}\left(\Psi_{t+1}^{l}\right)$ is directly related to $\lambda_{t}$, the Lagrange multiplier of the borrowing constraint (5).

If constraint (16) is not binding then $\lambda_{t}=0$. In this case equations (14) and (15) determine the optimal unconstrained capital levels $k_{t+1}^{u}$ and $l_{t+1}^{u}$. If $k_{t+1}^{u}$ is greater than $(1-\delta) k_{t}$, then the irreversibility constraint (3) is not binding, the Lagrange multiplier $\mu_{t}$ is equal to zero and $\left\{k_{t+1}^{*}, l_{t+1}^{*}\right\}$, the optimal investment choices, are determined by $\left\{k_{t+1}^{u}, l_{t+1}^{u}\right\}$. If $k_{t+1}^{u}$ is smaller than $(1-\delta) k_{t}$ then the irreversibility constraint is binding. $k_{t+1}$ is constrained to be equal to $(1-\delta) k_{t}$, and equations (14) and (15) can be solved to determine $l_{t+1}^{i c}$ and $\mu_{t}^{i c}$. In this case the optimal investment choices $\left\{k_{t+1}^{*}, l_{t+1}^{*}\right\}$ are determined by $\left\{(1-\delta) k_{t}, l_{t+1}^{i c}\right\}$. The collateral constraint is instead binding when financial wealth is not sufficient as a down payment for $k_{t+1}^{*}$ and $l_{t+1}^{*}$, even if $d_{t}=0$ :

$$
\left(1-\frac{\tau_{k}}{R}\right) k_{t+1}^{*}+l_{t+1}^{*}>w_{t}+(1-\delta) k_{t}
$$

In this case the constrained levels of capital $k_{t+1}^{c}$ and $l_{t+1}^{c}$ are such that:

$$
\left(1-\frac{\tau_{k}}{R}\right) k_{t+1}^{c}+l_{t+1}^{c}=w_{t}+(1-\delta) k_{t}
$$

and the solution is determined by the values $k_{t+1}^{c}, l_{t+1}^{c}, \lambda_{t}$ and $\mu_{t}$ that satisfy equations (3), (14), (15) and (22).

\section{A new test of financing constraints based on variable capital}

One important property of variable capital is that equation (15) is not directly affected by the irreversibility constraint of fixed capital. The financing constraints test developed in this paper 
uses this property plus the fact that the term $E_{t}\left(\Psi_{t+1}^{l}\right)$, which summarizes the effect of financing constraints on variable capital investment, is a monotonously decreasing and convex function of $w_{i, t}^{F}$, as stated in the following proposition:

Proposition 1 We define $w_{t}^{\max }\left(\theta_{t}, k_{t}\right)$ as the level of financial wealth such that the firm does not expect to be financially constrained now or in the future. It follows, for a given value of the state variables $\theta_{t}$ and $k_{t}$ and for $w_{t}^{F}<w_{t}^{\max }$, that $E_{t}\left(\Psi_{t+1}^{l}\right)$ is positive and is decreasing and convex in the amount of internal finance:

$$
\frac{\partial E_{t}\left(\Psi_{t+1}^{l}\right)}{\partial w_{t}^{F}}<0, \frac{\partial^{2} E_{t}\left(\Psi_{t+1}^{l}\right)}{\partial\left(w_{t}^{F}\right)^{2}}>0 \text { and } \lim _{w_{t}^{F} \rightarrow w_{t}^{M A X}} E_{t}\left(\Psi_{t+1}^{l}\right)=0
$$

Conversely if $w_{t}^{F} \geq w_{t}^{\max }$ then $E_{t}\left(\Psi_{t+1}^{l}\right)=0$

\section{Proof: see appendix 2.}

Proposition 1 applied to equation (15) establishes a link between financing imperfections and the real investment decisions of firms. It says that when a firm is financially constrained then the availability of internal finance increases the investment in variable capital and reduces its marginal return. It is important to note that proposition 1 cannot be applied to fixed capital investment because of the presence of the irreversibility constraint. If the irreversibility constraint is binding, then $k_{t+1}=(1-\delta) k_{t}$ and $\mu_{t}>0$. In this case a change in the intensity of financing constraints, that causes a change in $E_{t}\left(\Psi_{t+1}^{k}\right)$ in equation (14), affects the value of $\mu_{t}$ but does not affect fixed capital investment.

Therefore we propose a new financing constraints test that applies proposition 1 to variable capital investment decisions. If we take logs of both sides of equation (15) and we solve for $\ln l_{t+1}$ we obtain:

$$
\ln l_{t+1}=\frac{1}{1-\beta} \ln \frac{\beta}{R}+\frac{1}{1-\beta} \ln E_{t}\left(\theta_{t+1}\right)+\frac{\alpha}{1-\beta} \ln k_{t+1}-\frac{1}{1-\beta} \ln \left[1+E_{t}\left(\Psi_{t+1}^{l}\right)\right]
$$

Proposition 1 allows us to substitute $1+E_{t}\left(\Psi_{t+1}^{l}\right)$ with a negative and convex function of $\frac{w_{t}^{\max }}{w_{t}^{F}}$. We approximate it as follows:

$$
1+E_{t}\left(\Psi_{t+1}^{l}\right)=\left(w_{t}^{\max } / w_{t}^{F}\right)^{\eta}
$$


in which $\eta$ is an indicator of the intensity of the financing constraints. The more the firm is financially constrained (in the model, this corresponds to a lower value of $v$, which tightens the financing constraints), the more the investment of the firm is sensitive to internal finance (meaning that $E_{t}\left(\Psi_{t+1}^{l}\right)$ increases more rapidly as $w_{t}^{F}$ decreases) and the larger $\eta$ is. $w_{t}^{\max }$ is not observable in reality, but it is itself a function of the other state variables. Intuitively $w_{t}^{\max }$ increases in $E_{t}\left(\theta_{i, t+1}\right)$ because a higher productivity increases the financing needs of the firm, and conditional on $E_{t}\left(\theta_{i, t+1}\right)$ it decreases in $k_{t}$, because a higher existing stock of fixed capital implies that more financial wealth can be used to finance variable capital. Since $k_{t+1}$ is highly correlated with $k_{t}$, our simulations show that a good approximation of $w_{t}^{\max }$ is the following:

$$
w_{t}^{\max }=w^{\max }\left[E_{t}\left(\theta_{t+1}\right)\right]^{\zeta} k_{t+1}^{\omega}
$$

Using equations (24) and (25) in (23), and lagging equation (23) by one period, we obtain the following reduced form variable capital equation:

$$
\begin{gathered}
\ln l_{t}=\pi_{0}+\pi_{1} \ln E_{t-1}\left(\theta_{t}\right)+\pi_{2} \ln k_{t}+\pi_{3} \ln w_{t-1}^{F}+\varepsilon_{t} \\
\pi_{0} \equiv \frac{1}{1-\beta} \ln \left(\frac{\beta}{R} w^{\max }\right) ; \pi_{1} \equiv \frac{1-\eta \zeta}{1-\beta} ; \pi_{2} \equiv \frac{\alpha-\eta \omega}{1-\beta} ; \pi_{3} \equiv \frac{\eta}{1-\beta}
\end{gathered}
$$

The term $\varepsilon_{t}$ includes the approximation errors. When estimating equation (26) with the empirical data it may also include measurement errors as well as unobservable productivity shocks. Such problems are dealt with in the estimations in the empirical section of the paper.

The new financing constraints test is based on the coefficient $\pi_{3}$. In the absence of financing frictions $\eta$ is equal to zero. This implies that $\pi_{3}=0, \pi_{1}=\frac{1}{1-\beta}$ and $\pi_{2}=\frac{\alpha}{1-\beta}$. Therefore $\pi_{1}$ and $\pi_{2}$ can be used to recover the structural elasticities $\alpha$ and $\beta$. In the presence of financing constraints $\eta$ and $\pi_{3}$ are instead positive. The intuition is the following: suppose a financially unconstrained firm receives a positive productivity shock at time $t-1$, so that $\ln E_{t-1}\left(\theta_{t}\right)$ is high. This firm increases $l_{t}$ up to the point that the marginal return on variable capital is equal to its user cost. Alternatively a financially constrained firm can only invest in variable capital if it has financial wealth available. For this firm $\ln l_{t}$ is less sensitive to the productivity shock $\ln E_{t-1}\left(\theta_{t}\right)$ and is positively affected by the amount of financial wealth $\ln w_{t-1}^{F}$. It is important to note that the irreversibility of fixed capital amplifies the effect of financing frictions on variable 
capital, and it implies that variable investment may be significantly financially constrained even after a negative shock, when $\theta_{t-1}$ and $E_{t-1}\left(\theta_{t}\right)$ are low. The negative shock implies that $k_{t-1}$ is relatively high, and the firm would prefer to reduce it, but $k_{t}$ is constrained to be not smaller than $(1-\delta) k_{t-1}$. In this situation a financially unconstrained firm would choose a relatively high level of $l_{t}$, because the two factors of productions are complementary. In contrast a financially constrained firm is forced to cut variable capital when it has not enough financial wealth available, and therefore the lower $\ln w_{t-1}^{F}$ is, the lower $\ln l_{t}$ is.

This financing constraints test has the following useful properties: i) it does not require the estimation of marginal $q$, but only of the productivity shock $\theta$. Unlike $q, \theta$ is not a forward looking variable. Therefore any error in measuring the profitability of the firm probably implies a smaller measurement error in $\theta$ than in $q$. Moreover $\theta$ can be estimated from balance sheet data, and it can be easily applied to datasets of small privately owned firms not quoted on the stock market. ii) Although it is based on a simple reduced form investment equation, this test allows the recovery of the structural parameters $\alpha$ and $\beta$. The estimates of $\alpha$ and $\beta$ provide an additional robustness check of the validity of the model. iii) Simulation results presented in the next section show that equation (26) is also able to detect the intensity of financing constraints when fixed capital is subject to convex adjustment costs rather than to the irreversibility constraint. The intuition is that in both cases equation (26) is well specified, because the information concerning the adjustment costs of fixed capital is summarized by $k_{t}$.

\section{A Alternative testing strategy}

As an alternative to equation (26), one could transform equation (15) as follows:

$$
\beta \frac{y_{t}}{l_{t}}=R\left[1+E_{t-1}\left(\Psi_{t}^{l}\right)\right]+\varepsilon_{t}^{y}
$$

where $\varepsilon_{t}^{y} \equiv \beta \frac{E_{t-1}\left(y_{t}\right)-y_{t}}{l_{t}}$ is an expectational error. By taking logs and rearranging, we obtain the following:

$$
\log l_{t}=\log \beta+\log y_{t}-\log \left\{R\left[1+E_{t-1}\left(\Psi_{t}^{l}\right)\right]+\varepsilon_{t}^{y}\right\}
$$


Therefore $\varepsilon_{t}^{y}$ enters nonlinearly in equation (29). If $\varepsilon_{t}^{y}$ is small relative to $E_{t-1}\left(\Psi_{t}^{l}\right)$, one can approximate $\log \left\{R\left[1+E_{t-1}\left(\Psi_{t}^{l}\right)\right]+\varepsilon_{t}^{y}\right\}$ with $\log \left\{R\left[1+E_{t-1}\left(\Psi_{t}^{l}\right)\right]\right\}+\varepsilon_{t}^{y}$, and obtain the following:

$$
\ln l_{t}=\pi_{0}+\pi_{1} \ln y_{t}+\pi_{2} \ln w_{t-1}^{F}+\varepsilon_{t}^{y}
$$

In theory, equation (30) could be used for the purpose of estimating the intensity of financing constraints. However our simulations of the calibrated model indicate that $\varepsilon_{t}^{y}$ is likely to be large because its volatility is driven by the volatility of the idiosyncratic productivity shock. They also show that the nonlinearity of $\varepsilon_{t}^{y}$ in equation (29) may considerably reduce the precision of the financing constraints test based on equation (30), especially when the number of observations in the sample is small. Therefore in the empirical section of this paper we focus on the estimation of equation (26).

\section{Simulation results}

In this section we use the solution of the model to simulate the activity of many firms. These are ex ante identical and are subject to an idiosyncratic productivity shock that is uncorrelated across firms and autocorrelated for each firm. We simulate several industries in order to verify whether equation (26) is able to detect the intensity of financing constraints on firms investment. We adopt the same methodology commonly used in empirical applications since the seminal paper of Fazzari, Hubbard and Petersen (1988). We use a priori information to select a subsample of firms more likely to face financing imperfections, and then we compare the sensitivity of investment to internal finance for this group with respect to the other firms. All simulations assume that prices and interest rate are constant. As our objective is to analyze the effects of financing constraints at firm level, the partial equilibrium nature of this exercise does not restrict the analysis in any important way. In one set of simulated industries, firms become financially constrained when the borrowing constraint (5) is binding, and their internal finance is not sufficient to finance all profitable investment opportunities. In another set of industries, firms are not financially constrained because $v$ is so high that the borrowing constraint (5) is never binding with equality. We also make a further distinction. In one set of industries 
fixed capital is irreversible and in another, fixed capital is subject to the following quadratic adjustment costs function:

$$
\mu\left(i_{t}\right)=b \frac{1}{2}\left[\frac{i_{t}}{k_{t-1}}\right]^{2} k_{t-1}
$$

In the context of our model, equation (31) determines the following reduced form investment equation:

$$
\begin{gathered}
\frac{i_{t}}{k_{t-1}}=-\frac{1}{b}+\frac{1}{b} \frac{q_{t-1}}{1+\phi_{t-1}}+\Phi_{t-1} \\
\Phi_{t-1} \equiv \frac{v}{b} \frac{\lambda_{t-1}}{1+\phi_{t-1}} ; q_{t-1} \equiv E_{t-1}\left[\frac{d V_{t}\left(w_{t}, \theta_{t}, k_{t}\right)}{d k_{t}}\right]
\end{gathered}
$$

In the absence of financing frictions both $\Phi_{t-1}$ and $\phi_{t-1}$ are equal to zero, and equation (32) simplifies to a linear relationship between marginal $q$ and the investment rate:

$$
\frac{i_{t}}{k_{t-1}}=-\frac{1}{b}+\frac{1}{b} q_{t-1}
$$

The idiosyncratic shock is modeled as follows (in the remainder of the paper we include the subscript $i$ to indicate the $i-t h$ firm):

$$
y_{t}=\theta_{i, t}^{I}\left(\theta_{i, t} k_{t}^{\alpha} l_{t}^{\beta}\right) \text { with } \alpha+\beta<1
$$

$\theta_{i, t}$ is a persistent shock and $\theta_{i, t}^{I}$ is an i.i.d. shock:

$$
\begin{gathered}
\ln \theta_{i, t}=\rho \ln \theta_{i, t-1}+\varepsilon_{i, t} \\
0<\rho<1 ; \varepsilon_{i, t} \sim \operatorname{iid}\left(0, \sigma_{\varepsilon}^{2}\right) \text { for all } i \\
\ln \theta_{i, t}^{I}=\varepsilon_{i, t}^{I} \\
\varepsilon_{i, t}^{I} \sim i i d\left(0, \sigma_{\varepsilon^{I}}^{2}\right) \text { for all } i
\end{gathered}
$$

The persistent shock $\theta$ is necessary to match the volatility and the persistence in firm investment. The i.i.d. shock $\theta^{I}$ matches the volatility of profits and ensures that they are negative for a significant share of firms in the simulated industry. Both shocks are important because they 
allow the simulated firms to have realistic dynamics of both investment and financial wealth. If we only allow for the persistent shock $\theta$ (by setting $\sigma_{\varepsilon^{I}}^{2}=0$ ), not only is the volatility of profits of simulated firms too low, but these also never have negative profits, which instead are observed for a large share of firm-year observations in the sample used for the empirical analysis in the next section.

The dynamic investment problem is solved using a numerical method (see appendix 3 for details). The model is parameterized assuming that the time period is one year. Table I summarizes the choice of parameters. The risk-free real interest rate $r$ is equal to $2 \%$, which is the average real return on a 1-year US T bill between 1986 and 2005. The sum of $\alpha$ and $\beta$ matches returns to scale equal to 0.97 . This value is consistent with studies on disaggregated data that find returns to scale to be just below 1 (Burnside, 1996). Moreover, because in the model there are no fixed costs of production, even such a small deviation from constant returns is sufficient to generate, for the set of benchmark parameters, average profits in the simulated firms that are relatively large and consistent with the empirical evidence. $\beta$ is set to match the ratio of fixed capital over variable capital. In the model, variable capital fully depreciates in one period, and therefore we consider as variable capital the sum of materials cost and wages, and we consider as fixed capital land, buildings, plant and equipment. Using yearly data about manufacturing plants from the NBER-CES database (which includes information about the cost of materials), we calculate a fixed capital/variable capital ratio between 0.5 and 0.7 for the 19801996 period. The other parameters are the following: the depreciation rate of fixed capital $\delta$ is set equal to $0.12 ; b, \rho$ and $\sigma_{\varepsilon}$ match the average, standard deviation, and autocorrelation of the fixed investment rate of the US Compustat database, as reported in Gomes (2001); $\sigma_{\varepsilon^{I}}^{2}$ matches the standard deviation of the cash flow/fixed capital ratio; $v$ is set to match the average debt/assets ratio of US corporations; $\gamma$ is equal to 0.94 , implying that in each period a firm exits with $6 \%$ probability. This value is consistent with the empirical evidence about firms' turnover in the US (source: Statistics of U.S. Businesses, US Census Bureau). The second part of table I reports the matched moments. The simulated industries do not match perfectly the empirical moments, given the presence of nonlinearities in the mapping from the parameters to the moments, but 
they are sufficiently close for our purpose.

We simulate 50000 firm-year observations, which can be interpreted as an industry where we observe every firm in every period of activity, and where a firm that terminates its activity is replaced by a newborn firm. The initial wealth of a newborn firm is equal to $40 \%$ of the average fixed and variable capital of a financially unconstrained firm. This initial endowment ensures that financing constraints are binding for a non-negligible fraction of firms in the simulated industries. The initial fixed capital of a newborn firm is ex ante optimal, conditional on its initial wealth and the expectation as regards the initial productivity shock. Tables II-V report the estimation results from the simulated data. In these tables we do not report the standard deviations of the estimated coefficients, because all coefficients are strongly significant. Table II reports the estimation results of equation (26). It shows that the new test is always able to identify more financially constrained firms because the coefficient of $\ln w^{F}$ is positive in the industries with financing frictions and is otherwise equal to zero. In the bottom part of table II we compare the groups of most constrained firms and the complementary samples (the test statistic of the difference in the coefficients across groups is not reported because it is always significantly different from zero). We sort firms into groups of more financially constrained firms using the average value of the Lagrangian multiplier $\lambda_{i, t}$ :

$$
\bar{\lambda}_{i}=\sum_{i=1}^{T_{i}} \lambda_{i, t}
$$

where $T_{i}$ is the number of years of operation of firm $i$. In the industries with financing frictions, the financing constraint is not always binding. This is because firms accumulate wealth, and become progressively less likely to face a binding financing constraint. Therefore the higher $\bar{\lambda}_{i}$ is, the higher the intensity of financing problems for firm $i$.

The middle part of table II shows that the coefficient of $\ln w^{F}$ also identifies the intensity of financing constraints because its magnitude increases with the magnitude of $\bar{\lambda}_{i}$ in each industry. Intuitively, the higher the value of $\bar{\lambda}_{i}$, the more firm $i$ has observations with a binding financing constraint and the more variable capital is sensitive to financial wealth.

Table II also shows that the intensity of financing constraints, and hence also the sensitivity 
of variable capital to financial wealth, is on average larger in the industry with the irreversibility constraint than in the industry with convex adjustment costs. $\bar{\lambda}$ is higher in the former case because the irreversibility of fixed capital significantly increases the impact of financing frictions on variable capital investment. This happens not only because variable capital is the only factor of production that absorbs wealth fluctuations when the irreversibility constraint is binding, but also because when both constraints are binding a firm has too much fixed capital and not enough funds to invest in variable capital. The unbalanced use of the two factors of production reduces revenues and financial wealth and it increases the intensity of financing constraints. On the contrary, in the industry with quadratic adjustment costs, fixed investment is allowed to be negative and a firm can absorb a negative productivity shock by reducing both fixed and variable capital. The other estimated coefficients are consistent with the predictions of the model. In the industry without financing frictions, the estimated coefficients $\pi_{1}$ and $\pi_{2}$ are equal to $\frac{1}{1-\beta}$ and $\frac{\alpha}{1-\beta}$. In the industries with financing frictions, $\pi_{1}$ and $\pi_{2}$ are also nonlinear functions of the parameters $\zeta$ and $\omega$.

The approximations in equations (24) and (25) imply that equation (26) is correctly specified also in the presence of financing frictions. Therefore it is important to verify that these approximations are correct, and that they do not bias the estimated coefficient of $\ln w^{F}$. First, we verify that the approximation (24) is confirmed by the data. We show this by regressing $\log \left[1+E_{t}\left(\Psi_{t+1}^{l}\right)\right]$ on $\log \left(w_{t}^{\max } / w_{t}^{F}\right)$. The estimation yields $\eta=0.024$, with a very high goodness of fit $\left(R^{2}=0.977\right)$. This relationship is also shown graphically in figure 1 . Second, we take the logs of equation (25) and we estimate it with OLS. The $R^{2}$ of the regression is 0.91 , suggesting that the effect of the omitted variable $\ln w_{t}^{\max }$ in equation (26) should be absorbed by $\ln E_{t-1}\left(\theta_{t}\right)$ and $\ln k_{t}$, and should not bias significantly the coefficient of $\ln w_{t-1}^{F}$. We verify this claim by estimating a version of equation (26) where $\ln w_{t-1}^{\max }$ is explicitly included as a regressor. The bottom part of table II reports the estimation results, which are very similar to those illustrated above, and confirm that the coefficient of $\ln w_{t-1}^{F}$ is a reliable indicator of the intensity of financing constraints.

So far we have estimated the variable capital equation under the assumption that all variables 
are perfectly observable. However in reality the productivity shock $\theta_{t}$ is estimated using balance sheet data. Therefore table III reports the estimation results of equation (26) where $\ln E_{t-1}\left(\theta_{t}\right)$ is observed with noise:

$$
\ln E_{t-1}\left(\theta_{t}\right)^{*}=\ln E_{t-1}\left(\theta_{t}\right)+\kappa_{t-1}
$$

$\kappa_{t-1}$ is an i.i.d. error drawn from a normal distribution with mean 0 and variance $\sigma_{\kappa}^{2}$. The first column of table III replicates the results in the first column of table II. The second and third columns include a measurement error in $\ln E_{t-1}\left(\theta_{t}\right)$, with a "noise-to-signal" ratio (the ratio of $\sigma_{\kappa}^{2}$ to the variance of $\left.\ln E_{t-1}\left(\theta_{t}\right)\right)$ equal to 0.25 and 1 respectively. The next three columns repeat the same analysis for the economy with the irreversibility constraint. The results show that measurement errors cause a negative bias in the coefficient of $\ln w_{t-1}^{F}$. But because the bias is small, this coefficient is still a reliable indicator of the intensity of financing constraints. It is positive only for financially constrained firms, and a higher value of this coefficient for a group of firms always signals that this group is more financially constrained than the complementary sample. The only exception is in the third column: in this case when the measurement error is very large and firms are not very constrained (in the economy with quadratic adjustment costs $\bar{\lambda}$ is much smaller than $1 \%$ for all firms except the $20 \%$ most constrained ones), then the coefficient of $\ln w_{t-1}^{F}$ becomes negative, even though it is still increasing in the intensity of financing constraints.

The measurement error in the productivity shock has little effect on the coefficient of $\ln w_{t}^{F}$, because these two variables are nearly uncorrelated in the industries with financing constraints (see table II). This happens despite lagged cash flow, which is one of the determinants of financial wealth, being positively correlated to the productivity shock. There are two reasons for the low correlation between $\ln E_{t-1}\left(\theta_{t}\right)$ and $\ln w_{t-1}^{F}:$ i) firms that face financing imperfections accumulate financial wealth. This means that $w_{t-1}^{F}$ increases as the accumulated savings increase, and it becomes less sensitive to current fluctuations in cash flow; ii) equation (7) shows that the net worth of the firm is the sum of financial wealth $w_{t}^{F}$ and the residual value of fixed capital $(1-\delta) k_{t}$. Because the productivity shock is persistent, when $\theta_{t-1}$ and $E_{t-1}\left(\theta_{t}\right)$ are low, it is 
also likely that $\theta_{t-2}$ was low, so that the firm did not invest in fixed capital in the past, and a larger fraction of its wealth $w_{t-1}$ was invested in financial wealth $w_{t-1}^{F}$. The same reasoning applies when $E_{t-1}\left(\theta_{t}\right)$ is high. This "composition effect" implies a negative correlation between financial wealth and the productivity shock, and it counterbalances the positive correlation effect induced by the cash flow.

We have so far assumed that the residual value of capital is entirely collateralisable. In other words, there is no discount in the liquidation value of the firm's fixed assets. This assumption increases the leverage of the simulated firms and gets it closer to the empirical value. However, in reality, distressed firms often sell capital at fire-sale prices. Therefore in table IV we estimate equation (26) for industries with different values of $v$. The first column replicates the results of table II, with $v=1-\delta$. The second and third columns consider $v=0.85(1-\delta)$ and $v=0.7(1-\delta)$ respectively. They show that the lower the collateral value of capital, the higher the intensity of financing constraints and the coefficient of $\ln w_{t-1}^{F}$.

Summing up, the simulation results illustrated in tables II-IV suggest that the coefficient of $\ln w^{F}$ in equation (26) is a precise and reliable indicator of financing constraints, even in the presence of different types of adjustment costs of fixed capital and large observational errors in the productivity shock.

In the remainder of this section we compare the performance of this new test with a test based on the $q$ model of fixed capital:

$$
\frac{i_{i, t}}{k_{i, t-1}}=\alpha_{0}+\alpha_{1} q_{i, t-1}+\alpha_{2} \frac{w_{i, t-1}^{F}}{k_{i, t-1}}+\varepsilon_{i, t}
$$

Table V shows the estimation results of equation (40). In the $\frac{\sigma_{\varepsilon}}{\sigma q}=.25$ and $\frac{\sigma_{\varepsilon}}{\sigma q}=1$ columns there is a measurement error in $q$, with a noise-to-signal ratio equal to 0.25 and 1 respectively. In the first half of table $\mathrm{V}$, adjustment costs are quadratic. In the absence of financing frictions, the investment ratio $\frac{i_{i, t}}{k_{i, t-1}}$ is determined by equation (33) and therefore $q_{i, t-1}$ is a sufficient statistic for $\frac{i_{i, t}}{k_{i, t-1}}$. As a consequence, the coefficient of $\frac{w_{i, t-1}^{F}}{k_{i, t-1}}$ is equal to zero. In the presence of financing frictions the coefficient of $\frac{w_{i, t-1}^{F}}{k_{i, t-1}}$ is positive, significant, and increasing in the intensity of financing constraints, even in the presence of measurement errors, because $\frac{i_{i, t}}{k_{i, t-1}}$ is determined 
by equation (32), and $\frac{w_{i, t-1}^{F}}{k_{i, t-1}}$ is negatively correlated with the omitted term $1+\phi_{t-1}$. Therefore the first half of table $\mathrm{V}$ shows that when adjustment costs are convex, equation (40) does a good job of identifying financing constraints, even in the presence of measurement errors in $q$. On the contrary, in the second part of table $\mathrm{V}$ we consider the industry with irreversibility of fixed capital. Here $q$ is no longer a sufficient statistic for investment, and the coefficient of $\frac{w_{i, t-1}^{F}}{k_{i, t-1}}$ is positive for unconstrained firms because financial wealth conveys relevant information about investment. Moreover the coefficient of $\frac{w_{i, t-1}^{F}}{k_{i, t-1}}$ is small for financially constrained firms because for them, most of the fluctuations in wealth are absorbed by variable capital. As a consequence, fixed capital investment is more sensitive to financial wealth for less constrained than for more constrained firms for almost all of the sorting criteria. Thus equation (40) is not useful for identifying financing constraints, as is also found in Gomes (2001), Pratap (2003), Moyen (2004) and Hennessy and Whited (2006).

A more direct comparison with the previous literature is provided at the bottom of table $\mathrm{V}$, where we use average $Q$ to replace the unobservable marginal $q$, and we use the cash flow ratio $\frac{C F_{i, t-1}}{k_{i, t-1}}$ as the explanatory variable that captures financing frictions. The results show that the cash flow coefficient is highly significant both in the constrained and unconstrained industries, as also found by Moyen (2004). However such coefficient is not a good indicator of the presence of financing constraints in the presence of fixed capital irreversibility.

\section{Empirical evidence}

In this section we verify empirically the validity of the new test of financing constraints described in the previous section on a sample of small and medium Italian manufacturing firms. The sample is obtained by merging the two following datasets provided by Mediocredito Centrale: i) a balanced panel of more than 5000 firms with company accounts data for the 1982-1991 period. ${ }^{7}$ This is a subset of the broader dataset of the Company Accounts Data Service, which is the most reliable source of information on the balance sheet and income statements of Italian firms,

\footnotetext{
${ }^{7}$ The original sample had balance sheet data from 1982 to 1994, but we discarded the last three years of balance sheet data (1992, 1993 and 1994) from the sample, because of discrepancies and discontinuities in some of the balance sheet items, probably due to changes in accounting rules in Italy in 1992.
} 
and it has often been used in empirical studies on firm investment (e.g. Guiso and Parigi, 1999). ii) The four Mediocredito Centrale Surveys on small and medium Italian manufacturing firms. The surveys were conducted in 1992, 1995, 1998 and 2001. Each Survey covers the activity of a sample of more than 4400 small and medium manufacturing firms in the three previous years. The samples are selected balancing the criterion of randomness with that of continuity. Each survey contain three consecutive years of data. After the third year, $2 / 3$ of the sample is replaced and the new sample is then kept for the three following years.

The information provided in the surveys includes detailed qualitative information on property structure, employment, $R \& D$ and innovation, internationalization and financial structure. Among the financial information, each Survey asks specific questions about financing constraints. In addition to this qualitative information, Mediocredito Centrale also provides, for most of the firms in the sample, an unbalanced panel with some balance sheet data items going back as far as 1989. Examples of published papers that use the Mediocredito Centrale surveys are Basile, Giunta and Nugent (2003) and Piga (2002).

The main dataset used in this section is obtained by merging the firms in the balanced panel of the Centrale dei Bilanci with the firms in the 1992 Mediocredito Survey. The merged sample is composed of 812 firms, for which we have a unique combination of very detailed balance sheet data and detailed qualitative information about financing constraints. As a robustness check in section VI,E we consider an alternative dataset based on the 1998 and 2001 surveys. This dataset is larger but has less detailed balance sheet data and less precise information about financing constraints.

Regarding the main dataset, we eliminate firms without the detailed information concerning the composition of fixed assets (that do not distinguish between plant and equipment on the one side and land and building on the other side), ending up with 561 firms. We further eliminate firms that merged or firms that split during the sample period. The remaining sample is composed of 415 firms, virtually none of which is quoted on the stock markets. The information on financing constraints is contained in the investment section of the 1992 Survey. This section requests detailed information regarding the most recent investment projects aimed at improving 
the firm's production capacity. The firm indicates both the size of the project and the years in which such project was undertaken. $95 \%$ of all the answers concern projects undertaken between 1988 and 1991. Among the financial information, the firm is asked whether it had difficulties in financing such project because of:

a) "lack of medium-long term financing"; b) "high cost of banking debt"; c) "lack of guarantees".

It is worthwhile to notice that the selection of the firms in this sample is biased towards less financially constrained firms, for at least two reasons: i) the balanced panel only includes firms that have been continually in operation between 1982 and 1992, thus excluding new firms and firms that ceased to exist during the same period because of financial difficulties; ii) by eliminating mergers we eliminate firms in profitable businesses that merged with other companies because of their financing problems.

For the empirical specification of the financing constraints test we consider the following production function:

$$
y_{i, t}=\theta_{i, t} k_{i, t-1}^{\alpha} l_{i, t}^{\beta} n_{i, t}^{\gamma}
$$

All variables are in real terms, and are the following: $y_{i, t}=$ total revenues (during period $t$, firm $i$ ); $k_{i, t-1}=$ replacement value of plant, equipment and intangible fixed capital (end of period $t-1$, firm $i$ ); $l_{i, t}=$ cost of the usage of materials (during period $t$, firm $i$ ); $n_{i, t}=$ labor cost (during period $t$, firm $i$ ). Detailed information about all the variables is reported in appendix 4 . With respect to equation (1) in the theoretical model, equation (41) includes labor as a factor of production and it includes fixed capital as lagged by one period. Therefore we assume that fixed capital installed in period $t$ will become productive from period $t+1$ on. Under these assumptions the first order condition for variable capital is still represented by equation (15). By using equation (41) in (15) we get:

$$
\beta E_{t}\left(\theta_{t+1}\right) k_{t}^{\alpha} l_{t+1}^{\beta-1} n_{t+1}^{\gamma}=R\left[1+E_{t}\left(\Psi_{t+1}^{l}\right)\right]
$$

Equation (42) implies that proposition 1 still holds, conditional also on $n_{t}$. Moreover we can rearrange equation (42) and lag it by one period to obtain the following reduced form variable 
capital equation:

$$
\ln l_{i, t}=\pi_{0}+a_{i}+d_{t}+\pi_{1} \ln \theta_{i, t-1}+\pi_{2} \ln k_{i, t-1}+\pi_{3} \ln n_{i, t}+\pi_{4} \ln w_{i, t-1}^{F}+\varepsilon_{i, t}
$$

in which $\varepsilon_{i, t}$ is the error term, and $\ln \theta_{i, t-1}$ is the productivity shock, which is derived by taking the expectation of equation (35) and by noting that $\ln E_{t-1}\left(\theta_{i, t}\right)=\rho+\frac{\sigma_{\varepsilon}^{2}}{2}+\ln \theta_{i, t-1}$. The term $\rho+\frac{\sigma_{\varepsilon}^{2}}{2}$ is included in the constant term. The coefficient $\pi_{4}$ measures the intensity of financing constraints. Under the assumption of no financing constraints the reduced form coefficients $\pi_{1}, \pi_{2}$ and $\pi_{3}$ can be used to recover the structural parameters $\alpha, \beta$ and $\gamma$ :

$$
\pi_{1}=\frac{1}{1-\beta} ; \pi_{2}=\frac{\alpha}{1-\beta} ; \pi_{3}=\frac{\gamma}{1-\beta}
$$

In the model the user cost of variable capital is constant and equal to $R$ for financially unconstrained firms. In reality the user cost of capital may vary across firms and over time for several reasons unrelated to financing imperfections, such as transaction costs, taxes, and risk. Therefore in equation (43) we also include firm and year dummy variables, respectively $a_{i}$ and $d_{t}$. These capture, among other things, the changes in the user cost of capital across firms and over time for all the firms.

We estimate the productivity shock $\ln \theta_{i, t-1}$ from the Solow residual of the production function at the beginning of period $t$. The method used is robust to the presence of decreasing returns to scale and to heterogeneity in technology (see appendix 6 for details).

We compute $w_{t}^{F}$, the net financial wealth at the beginning of period $t$, by using the budget constraint (9) at time $t-1$ to substitute $b_{t}$ in (8):

$$
\begin{gathered}
w_{t}^{F}=\Pi_{t}+R_{t}\left(w_{t-1}^{F}-d_{t-1}\right) \\
\Pi_{t} \equiv y_{t}-R_{t}\left(l_{t}+i_{t-1}\right)
\end{gathered}
$$

In the model, $\Pi_{t}$ are profits generated from the investment in period $t-1$, and are realized at the beginning of period $t$. Therefore we estimate $\Pi_{t}$ as the operative profits during period $t-1$ (value of production minus the cost of production inputs). Moreover we estimate $\left(w_{t-1}^{F}-d_{t-1}\right)$ as the net short-term financial assets (after dividend payments) plus the stock of finished goods inventories at the beginning of period $t-1$. We include the stock of finished goods inventories 
because most of such goods will be transformed into cash flow during period $t-1$. $R_{t}$ is equal to one plus the average real interest rate during period $t-1$.

The concave transformation of wealth in equation (24) can be computed only if $w_{t}^{F}$ is positive. The simulations of the model show that, for reasonable parameter values, financial wealth is always positive in an economy with financing frictions. This is because such frictions at the same time reduce the maximum amount of borrowing and give incentive to firms to accumulate financial assets. The empirical data are consistent with this finding, because the variable $w_{t}^{F}$ is positive for $95.2 \%$ firm-year observations. Among the $4.8 \%$ negative observations, nearly half are excluded as outliers. In order to include the remaining negative observations, we consider an alternative definition of financial wealth based on the following modification of the borrowing constraint (9):

$$
b_{i, t+1} \leq v k_{i, t+1}+\bar{b}_{i}
$$

in which $\bar{b}_{i}$ represents the collateral value of firm $i$ in addition to the residual value of its assets. It can be interpreted as intangible collateral assets (for example from relationship lending). In this case it is appropriate to modify (24) as follows:

$$
\begin{aligned}
1+E_{t}\left(\Psi_{t+1}^{l}\right) & =\left(w_{t}^{\max } / \bar{w}_{t}^{F}\right)^{\eta} \text { if } \bar{w}_{t}^{F} \leq w^{\max } \\
\bar{w}_{t}^{F} & =w_{t}^{F}+\bar{b}_{i}
\end{aligned}
$$

We estimate $\bar{b}_{i}$ as the average borrowing of a firm in excess of the collateral value of the firm's fixed assets. The value $\bar{b}_{i}$ is found to be positive for 125 firms (30\% of the total). $\bar{w}_{t}^{F}$ is positive for $97.5 \%$ firm-year observations.

The estimation of equation (43) is complicated by the endogeneity of the regressors. First, all the regressors are most likely correlated to the firm-specific effect $a_{i}$. Second, $\ln n_{i, t}$ is endogenous because it is simultaneously determined with $\ln l_{i, t}$. Third, the other right-hand side variables are predetermined, but they may still be endogenous and correlated to $\varepsilon_{i, t}$. In other words, if all the relevant information about future expected productivity is summarized by $\ln \theta_{i, t-1}$, then $\varepsilon_{i, t}$ should be uncorrelated to the predetermined regressors. Otherwise an unobservable and persistent productivity shock in period $t-1$ may at the same time affect $w_{i, t-1}^{F}, k_{i, t-1}$ and 
$\varepsilon_{i, t}$ and cause an error-regressor correlation. The same problem may be caused by a persistent measurement error. In this case, a suitable estimation strategy is to first difference equation (43) in order to eliminate the unobservable firm-specific effect $a_{i}$, and then estimate it with a GMM estimation technique, using the available lagged levels and first differences of the explanatory variables as instruments. In this case, the set of instruments is different for each year and equation (43) is estimated as a system of cross sectional equations, each one corresponding to a different period $t$ (Arellano and Bond, 1991). More recent lags are likely to be better instruments, but they may be correlated with the error term if the unobservable productivity shock is very persistent. The test of overidentifying restrictions can be used to assess the orthogonality of the instruments with the error term. Moreover, under the assumption that $E\left(\Delta z_{i, t-j}, a_{i}\right)=0$, with $z=\left\{\ln \theta_{i, t}, \ln k_{i, t}, \ln w_{i, t}^{F}, \ln n_{i, t}\right\}, \Delta z_{i, t-j}$ is a valid instrument for equation (43) estimated in levels. Blundell and Bond (1998) propose a System GMM estimation technique that uses both the equation in level (instrumented using lagged first differences), and the equation in first differences (instrumented using lagged levels). They show, with Monte Carlo simulations, that the System GMM estimator is much more efficient than the simple GMM estimator when the regressors are highly persistent, and when the number of observations is small. These properties are particularly useful in our context. Table XV shows the test of the validity of the instruments for the estimation of equation (43). The upper part reports the p-value of the Hansen $J$ statistic that tests the orthogonality of the instruments. The bottom part of table XV reports the $\mathrm{F}$ statistic of the excluded instruments and the partial $R^{2}$ from Shea (1997). The table shows that the t- 1 to t-3 first differences as instruments for the equation in levels and the t-3 levels as instruments for the equation in first differences are not rejected by the orthogonality test and are sufficiently correlated to the regressors for the coefficients of equation (43) to be identified.

The primary objective of this empirical analysis is to verify that the coefficient of $\ln w_{i, t-1}^{F}$ in equation (43) is a precise indicator of the intensity of financing constraints. We do it by using the qualitative information provided by the Mediocredito Survey, which allows us to select firms more likely to be financially constrained. We also select firms according to some exogenous criteria commonly used in the previous literature as indicators of financing imperfections: i) dividend 
policy: firms that have higher cost (or rationing) of external finance than of internally generated finance are less likely to distribute dividends. Therefore the observed dividend policy should be correlated to the intensity of financing constraints. ii) Size and age: smaller and younger firms usually are more subject to informational asymmetries that may generate financing constraints. More specifically, we estimate equation (43) for subsamples of firms selected according to the dummy variable $D_{i, t}^{x}$, which is equal to 1 if the firm $i$ belongs to the specific group $x$, and zero otherwise. Among the direct criteria, $D^{h s}$ identifies firms that declare too high a cost of banking debt (13.7\% of all firms); $D^{l c}$ identifies firms with lack of medium-long term financing (13.2\% of all firms). ${ }^{8}$ Among the indirect criteria $D^{\text {age }}$ identifies firms founded after 1979 (16\% of all firms); $D^{\text {divpol }}$ identifies firms with zero dividends in any period (33.4\% of all firms); $D^{\text {size }}$ identifies firms with less than 65 employees (in 1992) (16\% of all firms).

We estimate the coefficients of equation (43) separately for each group of firms and for the complementary sample by interacting the above criteria with the explanatory variables, the constant, the yearly dummies and all the instruments. The $D^{h s}$ and $D^{l c}$ dummies are potentially endogenous, because an unobservable shock may at the same time be correlated with the likelihood of declaring financing constraints and with the error term in equation (43). However, this problem is not likely to bias the GMM estimates of equation (43) because we exclusively adopt cross sectional selection rules. In other words, Heckman (1979) shows that the selection bias can be represented as an omitted variable problem. But we do not allow firms to wander in and out of the constrained group, and therefore the omitted term is also constant over time for each firm and is absorbed by the fixed effect in the estimation. Because the GMM estimator used in the paper is based on first differences, it is robust to this type of cross sectional bias.

Another potential problem is measurement errors in the Survey. For example, at the time of the 1992 Survey, Mediocredito Centrale was a state-controlled financial institution whose main

\footnotetext{
${ }^{8}$ We do not select firms according to the question concerning "lack of guarantees" because only $2 \%$ of firms answer positively, and almost all of those are already included in the $D^{l c}$ and $D^{h s}$ groups.

Also, among all the firms in the sample $8 \%$ did not declare any investment project in the Mediocredito Survey, and therefore did not answer the questions about financing constraints. We keep these firms in the unconstrained sample, but one may also argue that perhaps some of these firms did not invest precisely because they may have been financially constrained. In order to control for this possibility we repeated the analysis excluding such firms from the sample, obtaining results very similar to those reported in the following sections.
} 
objective was to provide subsidized credit to small and medium firms. Therefore it may be that those firms declaring the problem of "lack of medium-long term financing" were actually sending strategic messages to the institution. However virtually all of the subsidized credit administrated by Mediocredito Centrale has been directed to the South of Italy. Indeed, among the firms in the 1992 Mediocredito Survey none of the firms from the North and Central Italy had benefited from any subsidized credit, while as much as $58.7 \%$ of the firms from the South had. Therefore this problem can be controlled for by excluding from the $D^{l c}$ group the firms from South Italy, which are $5 \%$ of the total (dummy $D_{- \text {south }}^{l c}$ ).

Another problem is that the $D^{l c}=1$ group may include some distressed firms that need more banking debt in order to survive, not because they need to finance a profitable project. The structure of the 1992 Survey, which only allows firms to declare financing problems if they actually undertook a new investment project, should avoid this problem. Nonetheless, we control for this by considering an alternative selection criterion that excludes from the $D^{l c}$ group also the $10 \%$ of firms with lower average ratio of gross profits over sales (dummy $D_{- \text {s.\&lowyeld }}^{l c}$ ).

Table VI illustrates the summary statistics. The whole sample is composed almost entirely of small firms. $50 \%$ of the firms have under 123 employees and $90 \%$ under 433 . Virtually all of these firms are privately owned and not quoted on the stock market. Likely financially constrained firms do not show significant differences with respect to the other firms in terms of size, growth rate of sales, investment rates, riskiness (volatility of output) and gross income margin. The most noticeable differences concern the financial structure. Firms that declare financing constraints are less wealthy, on average pay higher interest rates on banking debt and have a lower net income margin.

Table VII shows the estimation results of equation (43) for the whole sample and for the groups selected according to the "direct criteria" dummies. In the first column we use the data from the 1986-91 period, for which we have available the full set of instruments. In the other columns we estimate the model for the shorter 1988-91 period..$^{9}$

The full sample estimates in the first two columns show that the coefficients of $\ln \theta_{i, t}, \ln k_{i, t-1}$

\footnotetext{
${ }^{9}$ We restrict the sample because the Mediocredito Survey refers to the $1989-91$ period, but $5 \%$ of the investment projects surveyed actually started in 1988.
} 
and $\ln n_{i, t}$ are all significant and all have the expected sign and size. The coefficient of $\ln w_{i, t}^{F}$ is very small in magnitude and not significantly different from zero. This suggests that financing constraints do not affect a large share of firms in the sample, and is consistent with the information from the Mediocredito Survey, where only $22 \%$ of the firms state some problem in financing investment.

The remaining columns in table VII allow all the coefficients to vary across the subgroups of firms. In the third and fourth columns, the first set of coefficients is relative to the group of firms that declare the problem of too high cost of debt $\left(D^{h s}=0\right)$. The second set of coefficients are relative to all the regressors multiplied by $D^{h s}$. They represent the difference between the coefficient for the likely constrained firms $\left(D^{h s}=1\right)$ and that of the complementary sample $\left(D^{h s}=0\right)$. Therefore the $t$-statistic of this second set of estimates can be used to test the equality of the coefficients across groups. Column " 1 " uses the definition of financial wealth in equation (45), and column "2" includes also the observations with negative financial wealth using the broader definition in equation (48). The results show that the coefficient of $\ln w_{i, t}^{F}$ is positive, large in absolute value, and strongly significant for the likely constrained firms, and not significantly different from zero for the likely unconstrained firms. This result confirms the presence of financing constraints on the investment decisions of the firms that declare the problem of too high cost of debt in financing new investment projects. The last six columns report the results of the estimations that use the question about the lack of medium-long term credit to select financially constrained firms. Also in this case the coefficient of $\ln w_{i, t}^{F}$ is higher for the $D^{l c}=1$ group than for the complementary sample, and is always very significant after we correct for the possible presence of distressed and false reporting firms $\left(D_{- \text {south }}^{l c}\right.$ and $D_{-s . \& l o w y i e l d}^{l c}$ columns). By adding the coefficient of $\ln w_{i, t}^{F}$ to the coefficient of $\ln w_{i, t}^{F} * D_{i, t}$ we obtain the wealth coefficient for the constrained firms. This ranges from 0.17 to 0.28 for the $D^{h c}$ and $D_{-s . \& l o w y i e l d}^{l c}$ groups. These values are quite high compared to the same coefficient estimated for the constrained firms in the simulated industry (see table II). Simulation results in table IV show that the coefficient of $\ln w_{i, t-1}^{F}$ increases the tighter the collateral constraint (5) is. Therefore the empirical results may indicate that physical capital has a low collateral value for 
the firms in the 1992 Mediocredito Survey.

The estimated coefficients of $\ln k_{i, t-1}$ and $\ln \theta_{i, t-1}$ do not differ significantly across the two groups of firms. The coefficient of $\ln n_{i, t}$ is lower for the financially constrained firms, even though its value is always positive and consistent with the restrictions of the structural model. The fact that the estimated coefficient of $\ln w_{i, t}^{F}$ is zero for the whole sample and for the groups of unconstrained firms allows us to use $\widehat{\pi}_{1}, \widehat{\pi}_{2}$ and $\widehat{\pi}_{3}$ to estimate the structural parameters $\alpha, \beta$ and $\gamma$, using the restrictions in (44). The estimated $\widehat{\alpha}, \widehat{\beta}$ and $\widehat{\gamma}$ are reported in table VIII. These are consistent with the values directly estimated from the production function (see table XIV) and with the simple calculation of the elasticities using the factors shares of output, which are reported at the bottom of table VIII. The fact that the restrictions imposed by the structural model on the coefficients of $\ln \theta_{i, t}, \ln k_{i, t-1}$ and $\ln n_{i, t}$ are not rejected by the estimation results is important because it confirms the validity of our structural model. By using the estimate of $\widehat{\beta}=0.502$ we find $\widehat{\eta}$ to be equal to 0.13 for the $D^{h s}=1$ group . According to equation (24) this implies that if $w_{t}^{F}$ is $80 \%$ of $w_{t}^{M A X}$, then the shadow value of the binding borrowing constraint is equal to $2.9 \%$. This value increases to $9.4 \%$ if $w_{t}^{F}$ is $50 \%$ of $w_{t}^{M A X}$.

In table IX we estimate equation (43) for the 1986-91 sample, and we allow the coefficients to vary for the groups identified by the indirect criteria $D^{a g e}, D^{\text {divpol }}$ and $D^{\text {size }}$. The coefficient of $\ln w_{i, t}^{F}$ is always very small and always not significant for the likely unconstrained firms, while it is significantly positive for all the groups of likely constrained firms except the $D^{\text {divpol }}=1$ group. Regarding the other independent variables, the coefficients estimated for the likely unconstrained firms are always consistent with the restrictions of the structural model.

Among all the criteria used to split the sample, only the zero dividend policy has a limited ability to select firms with higher correlation between variable investment and internal finance. This weak result may be due to an endogeneity problem in the selection criterion. Another possible explanation of this finding is that for privately owned firms, the zero dividend policy is not a very useful indicator of the intensity of financing constraints. This is because for many firms in the sample the controlling shareholders are also the managers of the firms. These firms may choose zero dividends not because they are financially constrained, but because they have 
other ways of distributing revenues (such as in the form of compensation to managers) that are more tax efficient than dividends.

\section{Robustness checks}

Tables VII and IX show that the sensitivity of variable capital investment to internal finance is a useful indicator of the intensity of financing constraints. We argue that this finding is robust. First, this result is not likely to be driven by misspecification problems. The correct specification of equation (43) is confirmed by the fact that we obtain plausible estimates of the structural parameters of the model. Second, our findings are robust to the possible criticism that the coefficient of $\ln w_{i, t}^{F}$ is positive because the productivity shock is measured with error. The analysis of the simulated data indicates that the coefficient of $\ln w_{i, t}^{F}$ is not affected by the measurement error in $\theta_{i, t}$, because the two variables are uncorrelated. Our empirical results are consistent with this finding because the coefficient of $\ln w_{i, t}^{F}$ is always negative or not significantly different from zero, except for the group of likely financially constrained firms.

Therefore the claim that the results are driven by measurement error in $\theta$ requires that: i) $\ln \theta_{i, t}$ does not capture the unobservable productivity shock; ii) the unobservable productivity shock is highly correlated to $\ln w_{i, t}^{F}$ for likely constrained firms only, because these are on average more productive and grow faster than unconstrained firms. Assumption (i) is not very plausible, because the coefficient of $\ln \theta_{i, t}$ is significant and always has the expected sign and size for the likely unconstrained firms. Assumption (ii) is not plausible because table VI shows that firms more likely to be financially constrained have a similar profitability to the other firms. These considerations indicate that the differences in the coefficient of $\ln w_{i, t}^{F}$ across groups are unlikely to be driven by unobservable investment opportunities.

Another possible criticism is that the $\ln w_{i, t}^{F}$ coefficient captures changes in the user cost of capital that are not related to financing constraints. By first differencing and introducing year dummy variables we already take into account differences in the user costs of capital across firms or changes over time for all the firms. But one could object that the coefficient of $\ln w_{i, t}^{F}$ can be positive in the absence of financing imperfections if an increase in wealth is systematically 
correlated to a positive shock in the quality of the firm's projects that also makes its investment less risky. We argue that it would be hard to justify such a systematic relationship. More importantly, if this is true then we should observe a positive coefficient of wealth for all firms, while this does not happen in our sample. The only possibility would then be that such a systematic relationship only holds for likely financially constrained firms, because these are more risky, or because they are younger firms for which the quality of the management is very uncertain, and so their perceived riskiness is highly dependent on current performance. The results above allow us to reject both arguments. First, even though younger firms have a higher coefficient of $\ln w_{i, t}^{F}$, it is possible to show that if we exclude these firms from the sample (the $D^{a g e}=1$ observations), we still obtain the same results illustrated in tables VII and IX. ${ }^{10}$ Second, likely financially constrained firms do not seem, on average, riskier than the other firms (see table VI). Other robustness checks are illustrated in the following subsections $A-C$.

\section{A Alternative definition of wealth}

In this section we estimate equation (43) using a definition of wealth that does not include finished good inventories, called $\widetilde{w}_{i, t}^{F}$. Table $\mathrm{X}$ shows the estimation results relative to the groups selected according to both the direct and the indirect criteria. The narrower definition of wealth implies that $16 \%$ of the observations with negative values of $\widetilde{w}_{i, t}^{F}$ are not included. Most of these observations are from firms with low financial wealth that belong to the constrained groups ( $24 \%$ in the $D^{l c}=1$ group and $23 \%$ in the $D^{h c}=1$ group). This explains why the magnitude of the coefficient of $\ln \widetilde{w}_{i, t}^{F}$ for these groups is much reduced. However the results still largely confirm the findings of tables VII and IX. In particular the coefficient of $\ln \widetilde{w}_{i, t}^{F}$ is always negative and not significantly different from zero for the unconstrained sample. It is instead always larger for the constrained sample, and in three out of five cases also significantly so.

\section{B Collateral value of the assets}

The model developed in section III assumes that fixed capital is the only physical collateral available to the firm. However allowing for variable capital to be collateral does not change the

\footnotetext{
${ }^{10}$ Detailed results of the regressions performed after eliminating younger firms from the sample are available upon request.
} 
predictions of the model nor the interpretation of the results. If variable capital instead of fixed capital is the collateral of the firm, then equation (5) becomes:

$$
\begin{gathered}
b_{t+1} \leq v_{l} l_{t+1} \\
0<v_{l} \leq 1
\end{gathered}
$$

By substituting equation (49) holding with equality in the budget constraint (9) we get:

$$
d_{t}+\left(1-\frac{v_{l}}{R}\right) l_{t+1}+k_{t+1}=w_{t}^{F}+\left(1-\delta_{k}\right) k_{t-1}
$$

The larger $v_{l}$ is, the smaller is the financial wealth needed to finance variable investment. This is equivalent to assuming that $w^{\max }$ is smaller. Therefore if $v_{l}$ is sufficiently large then no firm is financially constrained and financial wealth should not be significant in equation (43) for both likely constrained and likely unconstrained firms. We find the opposite, confirming that $v_{l}$ is relatively small in our sample. This finding is realistic because even though variable inputs are partly financed with trade credit, which is usually considered a form of collateralized debt, in practice trade credit is very costly. The annualized interest rate that firms implicitly pay on trade credit is often found to be above $40 \%$ ( $\mathrm{Ng}$ et al., 1999).

\section{Estimations on the alternative dataset}

In this section we estimate equation (43) on the alternative sample based on the 1998 and 2001 Mediocredito Surveys. Each Survey asks the same type of questions about financing constraints, allowing us to pool them and obtain a larger sample. The disadvantage is that this alternative sample has less detailed balance sheet data: we do not have information about plant and equipment separated from land and building, we do not have information about distributed and retained earnings, and we have a less detailed description of the assets and liabilities.

Following the same procedure adopted for the main sample, we eliminate mergers and acquisitions and we include firms with at least 8 years of balance sheet data, so to have a complete set of instrumental variables in both surveys. Moreover this sample also contains a small fraction of firms with less than 15 employees (2.1\% of the total in this sample). The Employment 
Protection Law in Italy only applies to firms larger than 15 employees, and it imposes very high firing costs. Therefore many very small firms decide not to grow above the 15 -employee threshold in order to keep more flexibility (Schivardi and Torrini, 2004). This behavior distorts the relationship between financing frictions, productivity shock and investment and would bias the results of our regressions. Therefore we eliminate these firms from the sample, remaining with an unbalanced panel of 964 firms and 7305 observations.

In the finance section of the surveys firms are asked the following questions (in parentheses the percentage of positive answers in the 1998 and 2001 survey respectively):

1) "during the last year, did the firm desire to borrow more at the interest rate prevailing on the market?" $(13.5 \%, 19.3 \%)$

2) "If the previous answer was yes: was the firm willing to pay and higher interest rate in order to get additional credit?" $(5.0 \%, 6.9 \%)$

3) "During the last year, did the firm ask for more credit without obtaining it?" (3.5\%, $4.9 \%)$

With respect to the questions in the 1992 Survey, these questions are less informative about the financing constraints faced by the firms in financing investment, as they are not specifically linked to the investment section. Another inconvenience is that these questions explicitly refer to only one sample year rather than to the whole of the three years covered by the survey.

We find question (3) largely redundant, as few firms signal this problem and less than $0.5 \%$ of firms answer positively to question (3) without answering positively also to question (1). Question (2) is also a subset of question (1), but it may be able to identify a group of more financially constrained firms, with a higher shadow value of money. Therefore we use questions (1) and (2) to construct the following dummies:

$D_{i}^{\text {rationed }}=1$ if firm $i$ answers positively to question (1) in either the 1998 or the 2001 Survey and 0 otherwise.

$D_{i}^{\text {payhigher }}=1$ if firm $i$ answers positively to question (2) in either the 1998 or the 2001 Survey and 0 otherwise.

The fraction of firms in the constrained groups is equal to $23.3 \%$ and $8.9 \%$ for $D_{i}^{\text {rationed }}$ 
and $D_{i}^{\text {payhigher }}$ respectively. While we do not have the information about dividend policy for these firms, we can construct the dummies relative to the size and age criteria: $D^{a g e}$ identifies firms founded after 1982 ( $16 \%$ of all firms); $D^{\text {size }}$ identifies firms with less than 25 employees (16\% of all firms). For these indirect dummies we choose the thresholds in order to have a fraction of constrained firms equal to the fraction in the age and size dummies used before. Table XI illustrates the estimations of equation (43). We construct all variables following the same procedure adopted for the main sample. On exception is that we do not use the perpetual inventory method to compute the stock of fixed capital, because the time series is too short for most of the firms in the sample. Instead we evaluate it at book value. Moreover we do not subtract the dividend payments for the calculation of $w_{t-1}^{F}$, because we do not have this information for this sample.

The results obtained for the $D_{i}^{\text {rationed }}$ and $D_{i}^{\text {payhigher }}$ dummies confirm the validity of the financing constraints test. The coefficient of $\ln w_{t-1}^{F}$ is not significantly different from zero for the likely unconstrained firms and is always positive and significantly higher for the likely constrained firms. Moreover the estimate of the coefficient of $\ln w_{t-1}^{F}$ for the firms that answer yes to both questions 1 and 2 (the sum the coefficients of $\ln w_{t-1}^{F}$ and of $\ln w_{t-1}^{F} * D_{i, t}^{\text {payhigher }}$ ) is higher than for the firms that answer yes only to question 1 , as predicted by the model. The estimated coefficients of $\ln \theta_{i, t}, \ln k_{i, t-1}$ and $\ln n_{i, t}$ are always strongly significant for the likely unconstrained firms and do not show significant deviations for the likely constrained firms.

The coefficient of $\ln w_{t-1}^{F}$ was estimated to be between 0.17 and 0.28 in the panel based on the 1992 Survey. Instead the same coefficient is between 0.11 and 0.23 for the alternative panel of firms based on the 1998 and 2001 surveys. Moreover in the alternative panel the coefficient of $\ln w_{t-1}^{F}$ is always higher for younger and smaller firms than for the complementary samples, but the difference is significant in only one out of four cases.

Because in both panels the estimates for the likely unconstrained firms are consistent with the predictions of the model, we can interpret these findings as evidence that the intensity of financing constraints on firm investment was lower in the 1995-2000 period than in the 19881991 period. This may due to the increased efficiency of the Italian financial sector after 1992, 
driven by the liberalization of financial services in the Euro area. For example Jappelli and Pistaferri (2000) notice that until the beginning of the 90's the average down payment ratio in Italy for mortgaged debt was usually between 40 and 50 percent, as opposed to 20 percent in the US and 15 percent in the UK. However the same authors notice that since 1994 Italian banks started to offer mortgages with down payment requirements as low as 20 percent, in response to increased internal and international competition. This may have reduced considerably the financing frictions faced by small and young Italian firms.

\section{Conclusions}

In this paper we develop a new test to detect financing constraints on firm investment. The test is derived from a structural multifactor model of firm investment with financing imperfections and is based on a reduced form variable capital investment equation.

We solve the model using a numerical method and we simulate two industries, one with quadratic adjustment costs, the other with the irreversibility of fixed capital. Both industries are calibrated to match the US industry. The results of the simulations show that the correlation between variable capital investment and internal finance is a useful indicator of the intensity of financing constraints, even when firm investment opportunities are estimated with error, and regardless of the type of adjustment costs of fixed capital.

We verify the validity of this test on two samples of Italian manufacturing firms. First, the estimation results do not reject the restrictions imposed by the structural parameters. Second, the sensitivity of variable investment to internal finance is never significant, and is always very small, for the groups of firms a priori not expected to be financially constrained. By contrast, it is significantly greater than zero, and often large, for likely financially constrained firms. The fact that the reduced form parameters do not reject the restrictions imposed by the structural model implies that we can interpret the magnitude of this sensitivity as an indicator of the intensity of financing constraints.

One important property of this test is that it does not require the information about the market value of the firm. Because it requires only the information present in balance sheet data, 
it can be easily applied to small privately owned firms not quoted on the stock markets. This property is useful for the literature that studies the consequences of financing imperfections for aggregate fluctuations, such as the literature on the financial accelerator and that on the credit channel of monetary policy.

\section{References}

[1] Abel, A.B. and O. Blanchard (1986), "The Present Value of Profits and Cyclical Movements in Investment" Econometrica, 54(2), 249-73.

[2] Abel, A. and J.C. Eberly, 2002, Investment and q with Fixed Costs: An Empirical Analysis, Mimeo, Northwestern University.

[3] Abel, A. and J.C. Eberly, 2003, Q Theory Without Adjustment Costs \& Cash Flow Effects Without Financing Constraints, Mimeo, University of Pennsylvania.

[4] Abel, A. and J.C. Eberly, 2004, Investment, Valuation and Growth Options, Mimeo, Northwestern University.

[5] Alti, A., 2003, How Sensitive Is Investment to Cash Flow When Financing Is Frictionless, Journal of Finance, 58, 707-22.

[6] Arellano, M. and S. Bond, 1991, Some Tests of Specification for Panel Data: Monte Carlo Evidence and an Application to Employment Equations, Review of Economic Studies, 58, 277-97.

[7] Basile, R., Giunta, A. and J.B. Nugent, 2003, Foreign Expansion by Italian Manufacturing Firms in the Nineties: An Ordered Probit Analysis; Review of Industrial Organization, $2003,23,1-24$

[8] Barnett, S.A. and P Sakellaris, 1998, Non-linear response of firm investment to Q: testing a model of convex and non-convex adjustment costs, Journal of Monetary Economics.

[9] Berger, P.G., ; Ofek, E. and Itzhak Swary, 1996, Investor Valuation of the Abandonment Option, Journal of Financial Economics, 42, 257-87.

[10] Blundell, R. and S. Bond, 1998, Initial Conditions and Moment Restrictions in Dynamic Panel Data Models, Journal of Econometrics 87, 115-43.

[11] Bond, S., Klemm, A., Newton-Smith, R., Syed, M., and Vlieghe Gertjan, 2004, "The Roles of Expected Profitability, Tobin's Q and Cash Flow in Econometric Models of Company Investment", IFS working paper 04/12

[12] Burnside, C, 1996, Production Function Regressions, Returns to scale, and Externalities, Journal of Monetary Economics, 37, 177-201. 
[13] Caballero, R.J. and J.V. Leahy,1996. "Fixed Costs: The Demise of Marginal q," NBER Working Paper n.5508.

[14] Carpenter,R.E., Fazzari S.M. and B. Petersen (1998), "Financing Constraints and Inventory Investment: A Comparative Study with High-Frequency Panel Data", The Review of Economics and Statistics, 80, 513-519.

[15] Carpenter,R.E. and B. Petersen (2003), Is the Growth of Small Firms Constrained by Internal Finance?, Review of Economics and Statistics 84(2), 298-309.

[16] Erickson, T. and T. Whited, 2000, Measurement Error and the Relationship between Investment and q, Journal of Political Economy 108, 1027-57

[17] Fazzari S.M., Hubbard G.R. and B.C. Petersen, 1988, Financing Constraints and Corporate Investment, Brooking Papers on Economic Activity 1, 141-195.

[18] Gelos, R. and A. Werner, 2002, Financial Liberalization, Credit Constraints, and Collateral: Investment in the Mexican Manufacturing Sector, Journal of Development Economics, 67, $1-27$.

[19] Gilchrist, S and Himmelberg, C., 1998, Investment, Fundamentals, and Finance, in Bernanke, B. and Rotemberg, J. (eds), NBER Macro Annuals 1998, Cambridge, MIT press, 223-274.

[20] Gomes, J., 2001, Financing Investment, American Economic Review 91, 1263-1285.

[21] Guiso, L. and G. Parigi, 1999, Investment and Demand Uncertainty, Quarterly Journal of Economics, 114, 185-227.

[22] Hall, B.H. and J. Mairesse, 1996, Estimating the Productivity of Research and Development: An Exploration of GMM Methods Using Data on French \& United States Manufacturing Firms, NBER WP n.5501.

[23] Hayashi, F., 1982, Tobin's Marginal q and Average q: A Neoclassical Interpretation, Econometrica, 50(1), 213-24.

[24] Hart,O and J.H. Moore, 1998, Default and Renegotiation: a Dynamic Model of Debt, Quarterly Journal of Economics 113, 1-41.

[25] Heckman, J., 1979. Sample Selection Bias as a Specification Error, Econometrica 47, 153161.

[26] Hennessy, C., Levy, A. and T. Whited, 2006," Testing Q Theory with Financing Frictions", Forthcoming, Journal of Financial Economics.

[27] Hennessy, C. and T. Whited, 2006, "How Costly is External Financing? Evidence from a Structural Estimation", forthcoming, Journal of Finance. 
[28] Himmelberg, C.P. and B. Petersen, 1994, R\&D and Internal Finance: A Panel Study of Small Firms in High-Tech Industries, The Review of Economics and Statistics, 76(1), 38-51.

[29] Hubbard, G.R., 1998, Capital-Market Imperfections and Investment, Journal of Economic Literature 36, 193-225.

[30] Jappelli, T. and L. Pistaferri, 2000, The dynamics of household wealth accumulation in Italy, Fiscal Studies 21, 269-295.

[31] Kaplan, S. and L. Zingales, 1997, Do Investment-Cash Flow Sensitivities Provide Useful Measures of Financing Constraints?, Quarterly Journal of Economics 112, 169-215.

[32] Kaplan, S. and L. Zingales, 2000, Investment-Cash Flow Sensitivities Are Not Valid Measures Of Financing Constraints, The Quarterly Journal of Economics 115, 707-712.

[33] Kashyap, A., Lamont, O. and J. Stein, 1994,"Credit Conditions and the Cyclical Behavior of Inventories" The Quarterly Journal of Economics, 109, 565-92.

[34] Jaramillo, F., Schiantarelli, F. and A. Weiss, 1996, Capital Market Imperfections before and after Financial Liberalization: An Euler Equation Approach to Panel Data for Ecuadorian Firms, Journal of Development Economics, 51, 367-86

[35] Lízal, L. and J. Svejnar, 2002, Credit Rationing, And The Soft Budget Constraint: Evidence From Czech Panel Data, Review of Economics and Statistics, Vol. 84, Issue 2

[36] Moyen, Nathalie, 2004, "Investment-Cash Flow Sensitivities: Constrained versus Unconstrained Firms", Journal of Finance, vol. 59(5), pages 2061-2092.

[37] Ng, C.K., Smith J.K. and R.L.Smith, (1999) "Evidence on the Determinants of Credit Terms Used in Interfirm Trade" Journal of Finance, 54, 1109-29.

[38] Piga, G., 2002, Debt and Firms' Relationships: The Italian Evidence, Review of Industrial Organization, 20, 267-82.

[39] Pratap, S., 2003, Do Adjustment Costs Explain Investment-Cash Flow Insensitivity?, Journal of Economic Dynamics and Control, 27, 1993-2006.

[40] Schivardi, F. and R. Torrini, 2004, Threshold Effects and Firm Size: the Case of Firing Costs, CEP Discussion Papers n.633, Centre for Economic Performance, LSE.

[41] Shea, J., 1997, Instrument Relevance in Multivariate Linear Models: A Simple Measure, Review of Economics and Statistics, 49, 348-352.

[42] Stokey, N.L. and Robert E.L., 1989, Recursive Methods in Economic Dynamics, Harvard University Press.

[43] Whited, T., 2006, External Finance Constraints and the Intertemporal Pattern of Intermittent Investment, Forthcoming, Journal of Financial Economics. 
[44] Windmeijer, F., 2005, A finite sample correction for the variance of linear efficient two-step GMM estimators, Journal of Econometrics, 126, 25-51.

\section{Appendix 1}

In order to prove that a solution to the firm's investment problem exists and is unique, it is helpful to define the value function in (11) as follows:

$$
V_{t}\left(a_{t}, \theta_{t}, k_{t}, l_{t}\right)=\underset{k_{t+1}, l_{t+1}, a_{t+1}}{M A X} \pi_{t}+\frac{\gamma}{R} E_{t}\left[V_{t+1}\left(a_{t+1}, \theta_{t+1}, k_{t+1}, l_{t+1}\right)\right]
$$

We use equations $(1),(7),(8)$ and (9) to rewrite $\pi_{t}$ as a function of the state variables in periods $t$ and $t+1$ :

$$
\begin{gathered}
\pi_{t}=\theta_{t} k_{t}^{\alpha} l_{t}^{\beta}+a_{t}+\left(1-\delta_{k}\right) k_{t}-\frac{a_{t+1}}{R}-k_{t+1}-l_{t+1} \\
y_{t}=\theta_{t} k_{t}^{\alpha} l_{t}^{\beta} \text { with } \alpha+\beta<1
\end{gathered}
$$

The return function $\pi_{t}$ is real valued and continuous. Moreover it is bounded, because the production function is concave, the productivity shock $\theta_{t}$ is a stationary process, and assumption 1 ensures that $a_{t}$ is bounded. Finally equation (52) proves that $\pi_{t}$ is strictly increasing in the state variables at time $t$. Since constraints (5), (9) and (6) define a compact and convex feasibility set for the choice variables $l_{t+1}, k_{t+1}, b_{t+1}$ and $d_{t}$, it follows that the model satisfies the conditions for theorems 9.6 and 9.8 in Stokey and Lucas (1989), ensuring that the solution to the problem exists and is unique.

\section{Appendix 2}

Proof of proposition 1.

$w_{t}^{\max }$ is the level of financial wealth that allows the financing of all profitable investment projects. If $w_{t}^{F} \geq w_{t}^{\max }$ then $l_{t+1}=l_{t+1}^{*}\left(\theta_{t}, k_{t}\right)$ and $k_{t+1}=k_{t+1}^{*}\left(\theta_{t}, k_{t}\right)$. It follows that $w_{t}^{\max }$ satisfies the following condition:

$$
\left(1-\frac{\tau_{k}}{R}\right) k_{t+1}^{*}+l_{t+1}^{*}=w_{t}^{\max }+(1-\delta) k_{t}
$$

Suppose now that $w_{t}^{F}$ decreases below $w_{t}^{\max }$. Equation (54) cannot be satisfied with equality.

If the irreversibility constraint is binding with equality, then $k_{t+1}=(1-\delta) k_{t}$. In this case a reduction of $w_{t}^{F}$ causes a reduction in $l_{t+1}$ below $l_{t+1}^{*}$. The proof of proposition 1 follows by the fact that the production function (1) implies that $E_{t}\left(\frac{\partial y_{t+1}}{\partial l_{t+1}}\right)$ is decreasing and concave in $l_{t+1}$ conditional on $k_{t+1}=(1-\delta) k_{t}$.

If the irreversibility constraint is not binding, then both $l_{t+1}$ and $k_{t+1}$ must decrease as $w_{t}^{F}$ decreases below $w_{t}^{\max }$, because the two factors of production are complementary. This still 
implies that $E_{t}\left(\frac{\partial y_{t+1}}{\partial l_{t+1}}\right)$ is decreasing and concave in $w_{t}^{F}$, because the production function is concave in both factors.

\section{Appendix 3}

We briefly describe the method we use to solve the dynamic maximization problem of the firm. We discretise the state space of $w_{t}, k_{t}$ and $\theta_{t}$ in 20 grid points for each variable. We model $\theta^{I}$ as a two states i.i.d. process. We guess the value function $E_{t}\left[V_{t+1}\left(w_{t+1}, \theta_{t+1}, k_{t+1}\right)\right]$, and based on this guess we find the policy functions $k_{t+1}\left(w_{t}, \theta_{t}, k_{t}\right), l_{t+1}\left(w_{t}, \theta_{t}, k_{t}\right)$ and $b_{t+1}\left(w_{t}, \theta_{t}, k_{t}\right)$ that maximize $V_{t}\left(w_{t}, \theta_{t}, k_{t}\right)$. We use the maximized value function to reformulate a guess of $E_{t}\left[V_{t+1}\left(w_{t+1}, \theta_{t+1}, k_{t+1}\right)\right]$, and we repeat this procedure until convergence is achieved

Appendix 4

We describe here the variables used in the empirical analysis of the paper:

$p_{t}^{y} y_{i, t}$ : total revenues realized during year $t$, at current prices.

$p_{t}^{k} k_{i, t}$ : sum of the replacement value of: i) plants and equipment; ii) intangible fixed capital (Software, Advertising, Research and Development). We include in $p_{t}^{k} k_{i, t}$ all capital purchased before the end of time $t$. We compute the replacement value of capital by adopting the following perpetual inventory method:

$$
p_{t+1}^{k^{j}} k_{i, t+1}^{j}=p_{t}^{k^{j}} k_{i, t}^{j}\left(1+\pi_{t}^{j}\right)\left(1-\delta^{j}\right)+p_{t+1}^{k^{j}} i_{i, t+1}^{j}
$$

$j=\{1,2\}$, where $1=$ plant and equipment and $2=$ intangible fixed capital . $\pi^{1}=\%$ change in the producer prices index for agricultural and industrial machinery (source: OECD, from Datastream); $\pi^{2}=\%$ change in the producer prices index (source: OECD, from Datastream). $\delta^{j}$ are estimated separately for the 20 manufacturing sectors using aggregate annual data on the replacement value and the total depreciation of the capital (source: ISTAT, the Italian National Statistical Institute). Given that within each sector depreciation rates vary only marginally between years, we conveniently used the average over the sample period: $\delta^{1}$ ranges from $9.3 \%$ to $10.7 \%$, and $\delta^{2}$ from $8.4 \%$ to $10.6 \%$.

$p_{t}^{l} l_{i, t}$ : this variable measures the usage of variable inputs, at current prices, and is computed as follows: beginning-of-period $t$ input inventories (materials and work in progress), plus new purchases of materials in period $t$, minus end-of-period $t$ input inventories.

$p_{t}^{n} n_{i, t}$ : this variable includes the total cost of the labor in year $t$, at current prices.

$p_{t}^{w} w_{i, t}^{F}=$ Operative profits during period $t-1$ (value of production minus the cost of production inputs) plus the net short-term financial assets (after dividend payments) and the stock of finished goods inventories at the beginning of period $t-1$ multiplied by one plus the nominal interest rate.

$p_{t}^{w} \widetilde{w}_{i, t}^{F}$ is equal to $p_{t}^{w} w_{i, t}^{F}$ minus the stock of finished goods inventories.

In order to transform the variables into real terms, we used the following price indexes (source: ISTAT, the Italian National Statistical Institute):

$p_{t}^{y}$ : consumer price index relative to all products excluding services.

$p_{t}^{w}$ : same as $p_{t}^{y}$.

$p_{t}^{k}$ : producer price index of durable inputs.

$p_{t}^{n}$ : wage earnings index of the manufacturing sector.

$p_{t}^{l}$ : wholesale price index for intermediate goods. 


\section{Appendix 5}

In this section we illustrate the procedure used to estimate the productivity shock $\ln \theta_{i, t}$. First, we directly estimate the output elasticities to factor inputs $\alpha, \beta$ and $\gamma$. We consider the production function in equation (41). Table XII reports summary statistics of $y_{i, t}, k_{i, t}, l_{i, t}$ and $n_{i, t}$. By taking logs, we have the following linearized version of equation (41):

$$
\ln y_{i, t}=a_{i}+d_{t}+x_{s, t}+\alpha \ln k_{i, t-1}+\beta \ln l_{i, t}+\gamma \ln n_{i, t}+\varepsilon_{i, t}
$$

$a_{i}$ is the firm fixed effect. $d_{t}$ is the time effect and $x_{s, t}$ is the sector effect (we consider two digit sectors as classified by ISTAT). In order to allow some heterogeneity in the technology employed by firms in different sectors, equation (55) is separately estimated for seven groups of firms. Each group is composed of firms with as homogeneous as possible production activity. Table XIII shows the composition of the groups. Because we estimate equation (41) also for those firms that split or merged during the sample period, the total number is 561 firms. Equation (55) is estimated by first differencing and then using GMM with instrumental variables, on the sample from 1985 to 1991. We use both lagged first differences and levels as instruments for the equation in first differences. We consider lags -1 and -2 . This means that we exclude year 1982, in order to diminish possible distortions caused by the perpetual inventory method, and we have the data from 1983 and 1984 available as instruments. Table XIV reports estimation results. The first column is relative to the whole sample, while the next seven columns show the estimates of $\widehat{\alpha}, \widehat{\beta}$ and $\widehat{\gamma}$ for the seven groups separately. The Wald test shows that the restriction $\widehat{\alpha}+\widehat{\beta}+\widehat{\gamma}=1$ is rejected in favor of $\widehat{\alpha}+\widehat{\beta}+\widehat{\gamma}<1$ for all groups except group 7 . The estimated output elasticity of variable capital $\widehat{\beta}$ ranges between 0.29 and 0.56 , and in three groups it is higher than the output elasticity of labor $\widehat{\gamma}$. These high estimates of $\beta$ are quite common in firm-level estimates of the production function (see for example Hall and Mairesse, 1996). Output elasticity of fixed capital $\widehat{\alpha}$ ranges between 0.04 and 0.11 . This range of values is reasonable and consistent with the factor shares of output, given the amount of fixed capital as opposed to variable capital used in the production (see tables VIII and XII), and the difference in the user costs of fixed and variable capital caused by the difference in the depreciation factors. The yearly depreciation rate of plant and equipment is around $10 \%$, while the depreciation rate of the usage of materials is by construction equal to $100 \%$. The overidentifying restrictions are rejected for the estimation of the whole sample, but not for the estimations for each group of firms. Using the estimated elasticities $\widehat{\alpha}, \widehat{\beta}$ and $\widehat{\gamma}$ we compute total factor productivity for all the firm years observations:

$$
\widehat{T F T}_{i, t}=\ln y_{t}-\widehat{\alpha} \ln k_{i, t-1}+\widehat{\beta} \ln l_{i, t}-\widehat{\gamma} \ln n_{i, t}
$$

We then regress $\widehat{T F T}_{i, t}$ on fixed effects, year and sector dummy variables. The estimated residual from this regression is $\ln \theta_{i, t}$, which is the estimated productivity shock at the beginning of period $t+1$. 


\section{Figures}

Figure 1: Financial wealth and intensity of financing constraints

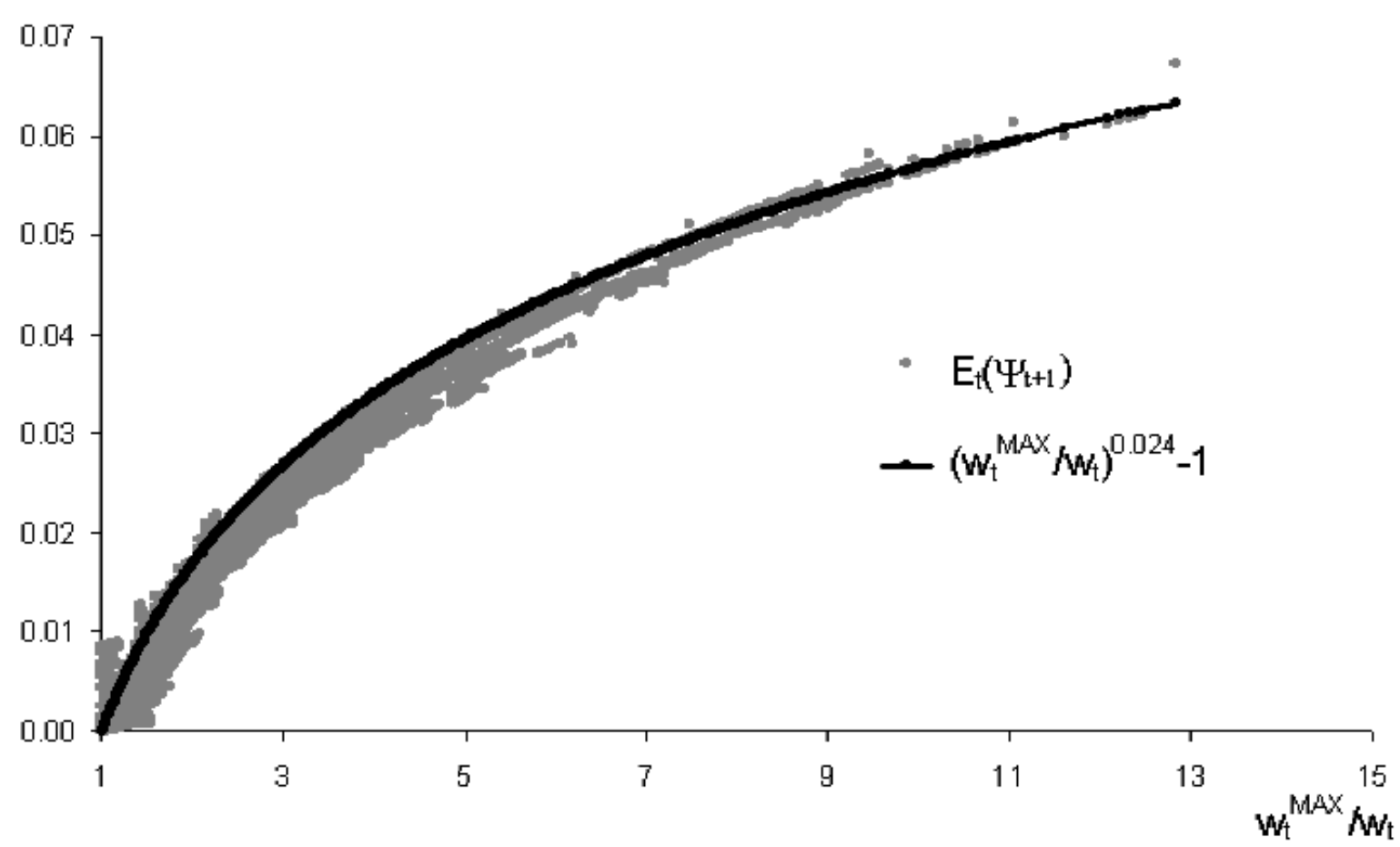

\section{Tables}

Table I: Calibrated parameters and matched moments.

\begin{tabular}{l|c||c||c||ccc}
\hline \hline & \multicolumn{2}{|c||}{ Parameter values } & Empirical restriction & \multicolumn{3}{c||}{ Matched moments } \\
\hline \hline & Q. adj. costs & Irrev. & & Data & Q.a.c & Irr. \\
\hline \hline$r$ & 0.02 & 0.02 & Real interest rate & 0.02 & 0.02 & 0.02 \\
$\alpha$ & 0.105 & 0.08 & Returns to scale & 0.97 & 0.97 & 0.97 \\
$\beta$ & 0.865 & 0.89 & Fixed capital/variable capital & $0.5-0.7$ & 0.82 & 0.68 \\
$\delta_{k}$ & 0.12 & 0.12 & Depr. of fixed capital & 0.12 & 0.12 & 0.12 \\
$\delta_{l}$ & 1 & 1 & Depr. of variab. capital & 1 & 1 & 1 \\
$b$ & 0.0002 & n.a. & Average(I/K) & 0.145 & 0.176 & 0.161 \\
$\rho$ & 0.8 & 0.95 & Std. $(\mathrm{I} / \mathrm{K})$ & 0.139 & 0.126 & 0.172 \\
$\sigma_{\varepsilon}$ & 0.02 & 0.01 & Autocorr. $(\mathrm{I} / \mathrm{K})$ & 0.239 & 0.222 & 0.200 \\
$\xi$ & 0.07 & 0.04 & Std.(CF/K) & 0.21 & 0.14 & 0.12 \\
$\tau$ & $1-\delta_{k}$ & $1-\delta_{k}$ & Debt/assets ratio & 0.20 & 0.15 & 0.16 \\
$\gamma$ & 0.94 & 0.94 & $6 \%$ firms exit each year & $6 \%$ & $6 \%$ & $6 \%$ \\
\hline
\end{tabular}


Table II: The variable capital model with financial wealth. No measurement errors.

\begin{tabular}{c|c|c}
\hline \hline \multicolumn{2}{c}{ regression: $\ln l_{i, t}=\pi_{0}+\pi_{1} \ln E_{t-1}\left(\theta_{i, t}\right)+\pi_{2} \ln k_{i, t}+\pi_{3} \ln w_{i, t-1}^{F}+\varepsilon_{i, t}$} \\
\hline \hline \multicolumn{2}{c}{ Industry without financing frictions } \\
\hline constant & -1.22 & Irreversibility \\
$\ln E_{i, t-1}\left(\theta_{t}\right)$ & 7.404 & -1.262 \\
$\ln k_{i, t}$ & 0.778 & 9.170 \\
$\ln w_{i, t-1}^{F}$ & 0.000 & 0.726 \\
$R^{2}$ & 1 & 0.000 \\
$\operatorname{corr}\left(\ln w_{i, t-1}^{F}, \ln E_{t-1}\left(\theta_{i, t}\right)\right)$ & 0.01 & 1 \\
$\operatorname{corr}\left(\ln C F_{i, t-1}, \ln E_{t-1}\left(\theta_{i, t}\right)\right)$ & 0.52 & -0.48 \\
\hline \multicolumn{2}{c}{ Industry with financing frictions } \\
\hline $\operatorname{constant}$ & -0.986 & 0.91 \\
$\ln E_{i, t-1}\left(\theta_{t}\right)$ & 6.256 & -0.294 \\
$\ln k_{i, t+1}$ & 0.802 & 2.357 \\
$\ln w_{i, t-1}^{F}$ & 0.006 & 0.903 \\
$R^{2}$ & 1 & 0.053 \\
$\operatorname{corr}\left(\ln w_{i, t-1}^{F}, \ln E_{t-1}\left(\theta_{i, t}\right)\right)$ & 0.03 & 0.98 \\
\hline \hline $\left.\operatorname{Cor} C F_{i, t-1}, \ln E_{t-1}\left(\theta_{i, t}\right)\right)$ & 0.30 & -0.05 \\
\hline
\end{tabular}

\begin{tabular}{c|cc|cc}
\hline \hline \multicolumn{2}{c|}{ Coefficient of $\ln w_{i, t}$ for groups of constrained firms and the complementary sample } \\
\hline \hline $80 \%$ most constr. firms & Constrained & $\begin{array}{c}\text { Compl. } \\
\text { sample }\end{array}$ & Constrained & $\begin{array}{c}\text { Compl. } \\
\text { sample }\end{array}$ \\
\hline $60 \%$ most constr. firms & $(\bar{\lambda}=0.5 \%)$ & $\begin{array}{c}0.002 \\
(\bar{\lambda}=0.09 \%)\end{array}$ & 0.055 & $\begin{array}{c}(\bar{\lambda}=1.9 \%) \\
(\bar{\lambda}=0.14)\end{array}$ \\
\hline & 0.011 & 0.003 & 0.066 & 0.027 \\
& $(\bar{\lambda}=0.6 \%)$ & $(\bar{\lambda}=0.1 \%)$ & $(\bar{\lambda}=2.4 \%)$ & $(\bar{\lambda}=0.3 \%)$ \\
\hline & 0.019 & 0.004 & 0.087 & 0.038 \\
& $(\bar{\lambda}=0.7 \%)$ & $(\bar{\lambda}=0.2 \%)$ & $(\bar{\lambda}=3.1 \%)$ & $(\bar{\lambda}=0.6 \%)$ \\
\hline & 0.037 & 0.005 & 0.172 & 0.046 \\
& $(\bar{\lambda}=1.0 \%)$ & $(\bar{\lambda}=0.3 \%)$ & $(\bar{\lambda}=4.2 \%)$ & $(\bar{\lambda}=0.9 \%)$ \\
\hline \hline
\end{tabular}

regression: $\ln l_{i, t}=\pi_{0}+\pi_{1} \ln E_{t-1}\left(\theta_{i, t}\right)+\pi_{2} \ln k_{i, t}+\pi_{3} \ln w_{i, t-1}^{F}+\pi_{4} \ln w_{i, t-1}^{\max }+\varepsilon_{i, t}$ Coefficient of $\ln w_{i, t-1}^{F}$ for groups of constrained firms and the complementary sample

\begin{tabular}{l|cc|cc}
\hline \hline & Constrained & $\begin{array}{c}\text { Compl. } \\
\text { sample }\end{array}$ & Constrained & $\begin{array}{c}\text { Compl. } \\
\text { sample }\end{array}$ \\
\hline $80 \%$ most constr. firms & 0.007 & 0.002 & 0.055 & 0.012 \\
\hline $60 \%$ most constr. firms & 0.011 & 0.003 & 0.063 & 0.027 \\
\hline $40 \%$ most constr. firms & 0.017 & 0.004 & 0.082 & 0.037 \\
\hline $20 \%$ most constr. firms & 0.043 & 0.005 & 0.161 & 0.045 \\
\hline
\end{tabular}

TSLS estimates on simulated data. $\ln k_{t}$ is instrumented by $\ln k_{t-1}$. All the estimated coefficients are statistically significant. The lower part of the table compares the estimates of $\pi_{3}$ for different subsamples selected according to the intensity of financing constraints. All the differences across coefficients are statistically significant. 
Table III: The variable capital model with financial wealth, with and without measurement errors in the productivity shock.

\begin{tabular}{|c|c|c|c|c|c|c|}
\hline \multicolumn{7}{|c|}{ "regression: $\ln l_{i, t}=\pi_{0}+\pi_{1} \ln E_{t-1}\left(\theta_{i, t}\right)^{*}+\pi_{2} \ln k_{i, t}+\pi_{3} \ln w_{i, t-1}^{F}+\varepsilon_{i, t}$} \\
\hline & \multicolumn{3}{|c|}{ Quadratic adjustment costs } & \multicolumn{3}{|c|}{ Irreversibility } \\
\hline \multicolumn{7}{|c|}{ Industry without financing frictions } \\
\hline & $\frac{\sigma_{\varepsilon}}{\sigma_{\theta_{t}^{e}}}=0$ & $\frac{\sigma_{\varepsilon}}{\sigma_{\theta_{t}^{e}}}=0.25$ & $\frac{\sigma_{\varepsilon}}{\sigma_{\theta_{t}^{e}}}=1$ & $\frac{\sigma_{\varepsilon}}{\sigma_{\theta_{t}^{e}}}=0$ & $\frac{\sigma_{\varepsilon}}{\sigma_{\theta_{t}^{e}}}=0.25$ & $\frac{\sigma_{\varepsilon}}{\sigma_{\theta_{t}^{e}}}=1$ \\
\hline constant & -1.22 & -1.03 & -0.451 & -1.262 & -0.38 & 0.28 \\
\hline $\ln E_{i, t-1}\left(\theta_{t}\right)^{*}$ & 7.404 & 6.064 & 1.620 & 9.170 & 4.241 & 0.464 \\
\hline $\ln k_{i, t}$ & 0.778 & 0.826 & 0.993 & 0.726 & 0.876 & 0.992 \\
\hline $\ln w_{i, t-1}^{F}$ & 0.000 & 0.000 & -0.001 & 0.000 & 0.000 & 0.000 \\
\hline$R^{2,-1}$ & 1 & 0.98 & 0.93 & 1 & 0.99 & 0.99 \\
\hline \multicolumn{7}{|c|}{ Industry with financing frictions } \\
\hline constant & -0.986 & -0.714 & 0.501 & -0.294 & -0.116 & 0.143 \\
\hline $\ln E_{i, t-1}\left(\theta_{t}\right)^{*}$ & 6.256 & 5.450 & 1.844 & 2.357 & 1.500 & 0.232 \\
\hline $\ln k_{i, t}$ & 0.802 & 0.810 & 0.851 & 0.903 & 0.935 & 0.982 \\
\hline $\ln w_{i, t-1}^{F}$ & 0.006 & 0.002 & -0.015 & 0.053 & 0.046 & 0.035 \\
\hline$R^{2}$ & 1 & 0.99 & 0.96 & 0.98 & 0.98 & 0.98 \\
\hline \multicolumn{7}{|c|}{ Coefficient of $\ln w_{i, t-1}^{F}$ for groups of constrained firms and the compl. sample } \\
\hline $80 \%$ most constr. firms & 0.008 & 0.004 & -0.013 & 0.055 & 0.048 & 0.037 \\
\hline compl. sample & 0.002 & -0.001 & -0.016 & 0.014 & 0.008 & 0.005 \\
\hline $60 \%$ most constr. firms & 0.011 & 0.009 & -0.008 & 0.066 & 0.059 & 0.048 \\
\hline compl. sample & 0.003 & -0.001 & -0.016 & 0.027 & 0.016 & 0.009 \\
\hline $40 \%$ most constr. firms & 0.019 & 0.017 & 0.003 & 0.087 & 0.080 & 0.067 \\
\hline compl. sample & 0.004 & 0.000 & -0.016 & 0.038 & 0.026 & 0.016 \\
\hline $20 \%$ most constr. firms & 0.037 & 0.039 & 0.040 & 0.172 & 0.165 & 0.151 \\
\hline compl. sample & 0.005 & 0.001 & -0.015 & 0.046 & 0.035 & 0.024 \\
\hline
\end{tabular}

TSLS estimates on simulated data. $\ln k_{t}$ is instrumented by $\ln k_{t-1}$. All the estimated coefficients are statistically significant. The lower part of the table compares the estimates of $\pi_{3}$ for different subsamples selected according to the intensity of financing constraints. All the differences across coefficients are statistically significant. When the coefficient $\pi_{3}$ is increasing in the intensity of financing constraints, and is positive for firms with financing frictions, it is reported in bold. 
Table IV: The variable capital model with financial wealth. Sensitivity to the collateral value of capital (no measurement errors, industry with financing frictions and irreversibility).

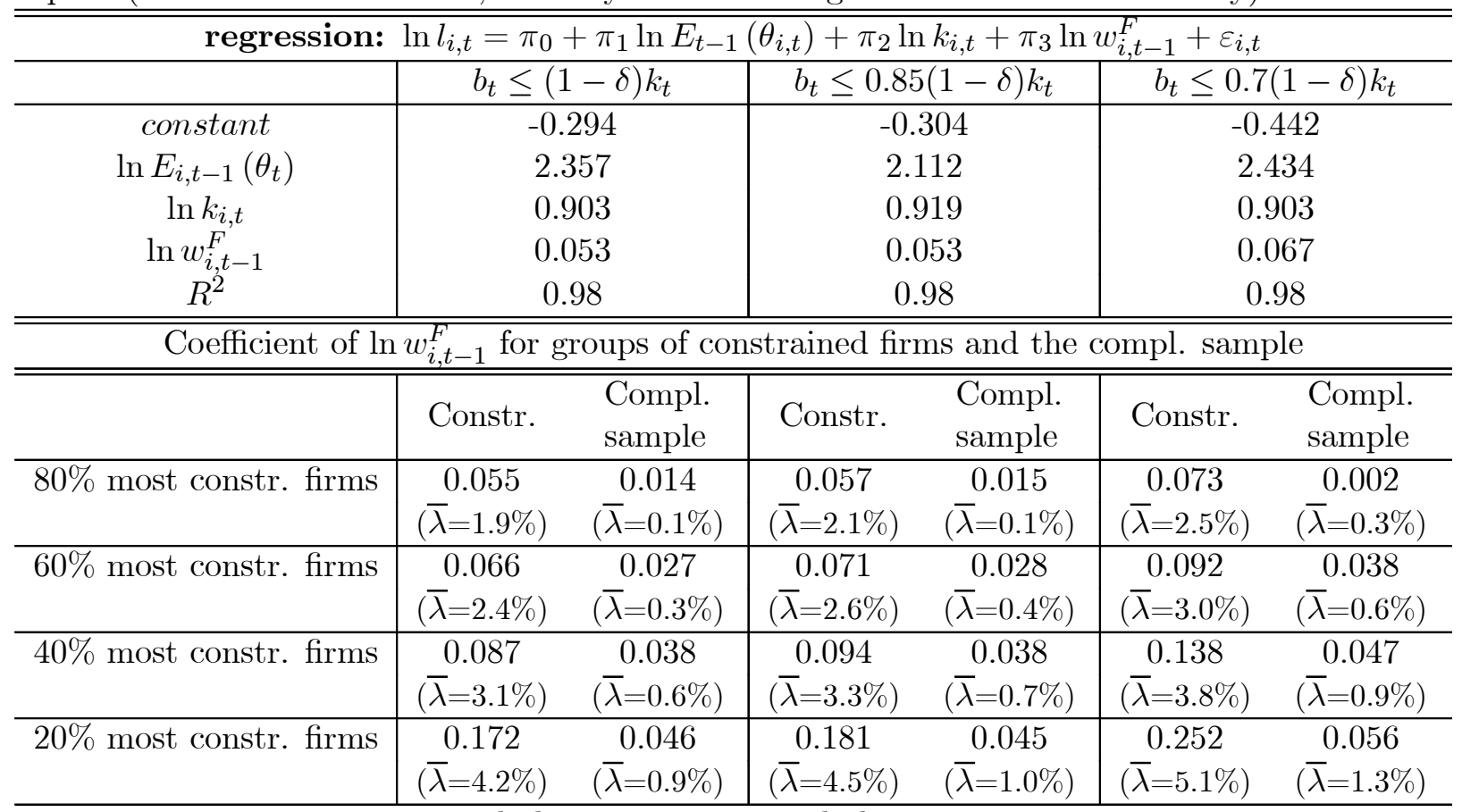

TSLS estimates on simulated data. $\ln k_{t}$ is instrumented by $\ln k_{t-1}$. All the estimated coefficients are statistically significant. The lower part of the table compares the estimates of $\pi_{3}$ for different subsamples selected according to the intensity of financing constraints. All the differences across coefficients are statistically significant. 
Table V: The $q$-model with financial wealth with and without measurement errors in $q$.

\begin{tabular}{|c|c|c|c|c|c|c|}
\hline \multicolumn{7}{|c|}{ 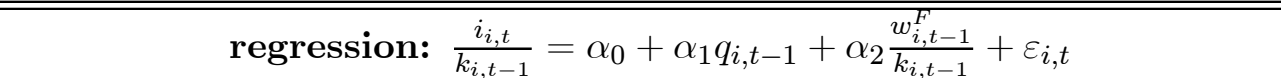 } \\
\hline & \multicolumn{3}{|c|}{ Quad. adjust. costs } & \multicolumn{3}{|c|}{ Irreversibility } \\
\hline \multicolumn{7}{|c|}{ Industry without financing frictions } \\
\hline & $\frac{\sigma_{\varepsilon}}{\sigma q}=0$ & $\frac{\sigma_{\varepsilon}}{\sigma q}=.25$ & $\frac{\sigma_{\varepsilon}}{\sigma q}=1$ & $\frac{\sigma_{\varepsilon}}{\sigma q}=0$ & $\frac{\sigma_{\varepsilon}}{\sigma q}=.25$ & $\frac{\sigma_{\varepsilon}}{\sigma q}=1$ \\
\hline constant & -9.97 & -9.36 & -4.81 & -3.76 & -3.55 & -1.83 \\
\hline$q_{i, t-1}$ & 9.97 & 9.36 & 4.88 & 3.98 & 3.76 & 2.01 \\
\hline$\frac{w_{i, t-1}^{F}}{k_{i, t-1}}$ & -0.001 & 0.000 & 0.005 & 0.009 & 0.010 & 0.015 \\
\hline$R^{2}$ & 1 & 0.94 & 0.49 & 0.12 & 0.11 & 0.07 \\
\hline \multicolumn{7}{|c|}{ Industry with financing frictions } \\
\hline constant & -0.95 & -0.86 & -0.29 & -1.09 & -1.01 & -0.41 \\
\hline$q_{i, t-1}$ & 1.01 & 0.928 & 0.423 & 1.20 & 1.12 & 0.55 \\
\hline$\frac{w_{i, t-1}^{F}}{k_{i, t-1}^{F}}$ & 0.020 & 0.018 & 0.007 & 0.006 & 0.006 & 0.002 \\
\hline$R^{R_{i, t-1}}$ & 0.28 & 0.26 & 0.12 & 0.15 & 0.14 & 0.07 \\
\hline \multicolumn{7}{|c|}{ Coefficient of $\frac{w_{i, t-1}^{F}}{k_{i, t-1}}$ for groups of constrained firms and the compl. samples } \\
\hline $80 \%$ most constr. firms & 0.028 & 0.026 & 0.015 & 0.005 & 0.005 & 0.002 \\
\hline complementary sample & 0.013 & 0.012 & 0.003 & 0.015 & 0.012 & 0.005 \\
\hline $60 \%$ most constr.firms & 0.041 & 0.041 & 0.035 & 0.007 & 0.006 & 0.001 \\
\hline complementary sample & 0.015 & 0.013 & 0.003 & 0.008 & 0.007 & 0.003 \\
\hline $40 \%$ most constr. firms & 0.072 & 0.074 & 0.084 & 0.008 & 0.007 & 0.000 \\
\hline complementary sample & 0.016 & 0.014 & 0.004 & 0.008 & 0.007 & 0.003 \\
\hline $20 \%$ most constr. firms & 0.122 & 0.132 & 0.168 & 0.042 & 0.041 & 0.027 \\
\hline complementary sample & 0.017 & 0.016 & 0.005 & 0.008 & 0.007 & 0.003 \\
\hline
\end{tabular}

regression using average $Q: \frac{i_{i, t}}{k_{i, t-1}}=\alpha_{0}+\alpha_{1} Q_{i, t-1}+\alpha_{2} \frac{C F_{i, t-1}}{k_{i, t-1}}+\varepsilon_{i, t}$

\begin{tabular}{l|lll|lll}
\hline \hline \multicolumn{2}{c}{ Coefficient of $\frac{w_{i, t-1}^{F}}{k_{i, t-1}}$ for groups of constrained firms and the compl. samples } \\
\hline $80 \%$ most constr. firms & $\mathbf{0 . 5 5 6}$ & $\mathbf{0 . 5 6 2}$ & $\mathbf{0 . 5 8 9}$ & 0.592 & 0.611 & 0.704 \\
\hline complementary sample & $\mathbf{0 . 5 3 3}$ & $\mathbf{0 . 5 3 7}$ & $\mathbf{0 . 5 5 6}$ & 0.625 & 0.630 & 0.655 \\
\hline $60 \%$ most constr. firms & $\mathbf{0 . 5 6 5}$ & $\mathbf{0 . 5 7 1}$ & $\mathbf{0 . 5 9 5}$ & 0.570 & 0.596 & 0.706 \\
\hline complementary sample & $\mathbf{0 . 5 3 1}$ & $\mathbf{0 . 5 3 5}$ & $\mathbf{0 . 5 5 7}$ & 0.635 & 0.641 & 0.676 \\
\hline $40 \%$ most constr. firms & $\mathbf{0 . 5 6 9}$ & $\mathbf{0 . 5 7 5}$ & $\mathbf{0 . 5 9 5}$ & 0.551 & 0.582 & 0.707 \\
\hline complementary sample & $\mathbf{0 . 5 4 0}$ & $\mathbf{0 . 5 4 4}$ & $\mathbf{0 . 5 6 8}$ & 0.627 & 0.637 & 0.682 \\
\hline 20\% most constr. firms & $\mathbf{0 . 5 7 8}$ & $\mathbf{0 . 5 8 2}$ & $\mathbf{0 . 5 9 5}$ & 0.546 & 0.581 & 0.705 \\
\hline complementary sample & $\mathbf{0 . 5 4 5}$ & $\mathbf{0 . 5 5 0}$ & $\mathbf{0 . 5 7 4}$ & 0.613 & 0.626 & 0.684 \\
\hline
\end{tabular}

OLS estimates on simulated data. All the estimated coefficients are statistically significant. The lower part of the table compares the estimates of $\alpha_{2}$ for different subsamples selected according to the intensity of financing constraints. All the differences across coefficients are statistically significant. When the coefficient $\alpha_{2}$ is increasing in the intensity of financing constraints, and is positive for firms with financing frictions, it is reported in bold. $Q_{i, t}=$ $V_{i, t} / w_{i, t} ; C F_{i, t}=y_{i, t}-r \frac{b_{i, t}}{R}$ 
Table VI: Summary statistics, years 1982-1991.

\begin{tabular}{l||c|cc}
\hline \hline & All firms & $D^{h s}=1$ & $D^{l c}=1$ \\
\hline \hline Mean fixed assets & \\
Median fixed assets & 6331 & 3136 & 4140 \\
Mean number of employees & 2442 & 2200 & 3064 \\
Median number of employees & 207 & 141 & 175 \\
90th percentile of employees & 423 & 119 & 131 \\
Short term banking debt/K & $0.50(0.15)$ & $0.54(0.13)$ & $0.51(0.14)$ \\
Long term banking debt/K & $0.10(0.08)$ & $0.11(0.09)$ & $0.11(0.07)$ \\
Average cost of debt ${ }^{2}$ & $.066(.035)$ & $.075(.037)$ & $.076(.036)$ \\
Gross income margin & $.066(.058)$ & $.065(.046)$ & $.068(.063)$ \\
Net income margin & $.018(.05)$ & $.01(.034)$ & $.014(.05)$ \\
Net sales growth & $0.11(0.19)$ & $0.11(0.17)$ & $0.12(0.20)$ \\
Financial wealth/K & $1.50(1.64)$ & $1.11(1.02)$ & $1.19(1.06)$ \\
Cash Flow/K & $0.41(0.57)$ & $0.29(0.26)$ & $0.35(0.43)$ \\
Fixed Investment/K & $0.30(0.34)$ & $0.28(0.30)$ & $0.30(0.28)$ \\
Volatility of output & $1.18(0.22)$ & $1.17(0.24)$ & $1.21(0.25)$ \\
\hline Number of firms & 415 & 63 & 56 \\
\hline Number of observations & 4150 & 630 & 560 \\
\hline \hline
\end{tabular}

Standard deviations in parentheses. $\mathrm{K}=$ fixed assets. Financial wealth= operative profits during period $t-1$ (value of production minus the cost of production inputs) plus the net short-term financial assets (after dividend payments) and the stock of finished goods inventories at the beginning of period $t-1$ multiplied by one plus the nominal interest rate. 1) Largest $1 \%$ and smallest $1 \%$ excluded from the computation of this statistic. 2) Interest paid on banking debt divided by total banking debt. Average on the 1989-91 period. 3) Values are in billions of Italian Lire, 1982 prices. 1 Billion lire was equal to 0.71 million US\$ at the 1982 exchange rate. 4) Average of the standard deviation of the growth rate of sales. 
Table VII: Financing constraints test: direct revelation criteria.

\begin{tabular}{|c|c|c|c|c|c|c|c|c|c|c|}
\hline \multicolumn{11}{|c|}{$\begin{array}{r}\text { Regression: } \\
-1+\pi_{2} \ln k_{i, t}\end{array}$} \\
\hline & & \multicolumn{9}{|c|}{ 1988-1991 sample } \\
\hline & All & All & \multicolumn{2}{|c|}{ 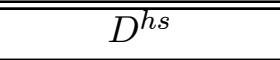 } & & & \multicolumn{2}{|c|}{$D_{- \text {south }}^{l c}$} & \multicolumn{2}{|c|}{ 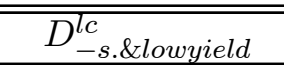 } \\
\hline & $(86-91)$ & $(88-91)$ & (1) & (2) & (1) & (2) & (1) & (2) & (1) & (2) \\
\hline $\ln k_{i, t-1}$ & $\begin{array}{c}0.30^{* * *} \\
(3.6)\end{array}$ & $\begin{array}{l}0.17^{*} \\
(1.9)\end{array}$ & $\begin{array}{l}0.08 \\
(0.8)\end{array}$ & $\begin{array}{l}0.05 \\
(0.5)\end{array}$ & $\begin{array}{l}0.13 \\
(1.4)\end{array}$ & $\begin{array}{c}0.18^{* *} \\
(2.0)\end{array}$ & $\begin{array}{l}0.15 \\
(1.5)\end{array}$ & $\begin{array}{c}0.18^{* *} \\
(1.9)\end{array}$ & $\begin{array}{l}0.16^{*} \\
(1.7)\end{array}$ & $\begin{array}{c}0.25^{* *} \\
(2.3)\end{array}$ \\
\hline $\ln n_{i, t}$ & $\begin{array}{c}0.62^{* * *} \\
(5.1)\end{array}$ & $\begin{array}{c}0.66^{* * *} \\
(4.8)\end{array}$ & $\begin{array}{c}0.86^{* * *} \\
(5.6)\end{array}$ & $\begin{array}{c}0.99^{* * *} \\
(6.3)\end{array}$ & $\begin{array}{c}0.82^{* * *} \\
(5.4)\end{array}$ & $\begin{array}{c}0.66^{* * *} \\
(4.6)\end{array}$ & $\begin{array}{c}0.81^{* * *} \\
(5.2)\end{array}$ & $\begin{array}{c}0.80^{\text {*** }} \\
(4.6)\end{array}$ & $\begin{array}{c}0.77^{* * *} \\
(5.1)\end{array}$ & $\begin{array}{c}0.74^{* * *} \\
(5.3)\end{array}$ \\
\hline $\ln \theta_{i, t-1}$ & $\begin{array}{c}1.94^{* *} \\
(2.0)\end{array}$ & $\begin{array}{l}1.57^{*} \\
(1.7)\end{array}$ & $\begin{array}{l}1.56^{*} \\
(1.6)\end{array}$ & $\begin{array}{l}2.01^{*} \\
(1.8)\end{array}$ & $\begin{array}{c}1.80^{* *} \\
(2.0)\end{array}$ & $\begin{array}{c}2.27^{* * *} \\
(2.6)\end{array}$ & $\begin{array}{c}1.99^{* *} \\
(2.1)\end{array}$ & $\begin{array}{c}2.43^{* *} \\
(2.5)\end{array}$ & $\begin{array}{c}1.99^{* *} \\
(2.1)\end{array}$ & $\begin{array}{c}2.72^{* * *} \\
(2.7)\end{array}$ \\
\hline $\ln w_{i, t-1}^{F}$ & $\begin{array}{l}0.01 \\
(0.4)\end{array}$ & $\begin{array}{l}-0.02 \\
(-0.5)\end{array}$ & $\begin{array}{l}-0.05 \\
(-1.5)\end{array}$ & $\begin{array}{l}0.02 \\
(0.4)\end{array}$ & $\begin{array}{l}-0.03 \\
(-0.7)\end{array}$ & $\begin{array}{l}0.00 \\
(0.1)\end{array}$ & $\begin{array}{l}-0.02 \\
(-0.6)\end{array}$ & $\begin{array}{l}0.03 \\
(0.5)\end{array}$ & $\begin{array}{l}-0.03 \\
(-0.8)\end{array}$ & $\begin{array}{l}0.03 \\
(0.7)\end{array}$ \\
\hline $\ln k_{i, t-1} * D_{i, t}$ & & & $\begin{array}{l}0.17 \\
(0.7)\end{array}$ & $\begin{array}{l}0.10 \\
(0.5)\end{array}$ & $\begin{array}{l}0.29 \\
(1.4)\end{array}$ & $\begin{array}{l}0.22 \\
(1.0)\end{array}$ & $\begin{array}{l}0.25 \\
(1.2)\end{array}$ & $\begin{array}{l}0.22 \\
(1.0)\end{array}$ & $\begin{array}{l}0.25 \\
(1.0)\end{array}$ & $\begin{array}{l}0.14 \\
(0.7)\end{array}$ \\
\hline $\ln n_{i, t} * D_{i, t}$ & & & $\begin{array}{l}-.49^{* *} \\
(-2.3)\end{array}$ & $\begin{array}{c}-.63^{* * *} \\
(-2.6)\end{array}$ & $\begin{array}{c}-.51^{* * *} \\
(-2.8)\end{array}$ & $\begin{array}{l}-.26 \\
(-0.9)\end{array}$ & $\begin{array}{c}-0.46^{* *} \\
(-2.5)\end{array}$ & $\begin{array}{c}-0.43^{* *} \\
(-2.1)\end{array}$ & $\begin{array}{c}-0.48^{* *} \\
(-2.2)\end{array}$ & $\begin{array}{l}-0.37^{*} \\
(-1.8)\end{array}$ \\
\hline $\ln \theta_{i, t-1} * D_{i, t}$ & & & $\begin{array}{l}-1.34 \\
(-0.4)\end{array}$ & $\begin{array}{l}-2.53 \\
(-0.6)\end{array}$ & $\begin{array}{l}5.23 \\
(0.9)\end{array}$ & $\begin{array}{l}5.82 \\
(1.1)\end{array}$ & $\begin{array}{l}4.17 \\
(0.7)\end{array}$ & $\begin{array}{l}4.52 \\
(0.5)\end{array}$ & $\begin{array}{l}5.59 \\
(0.8)\end{array}$ & $\begin{array}{l}4.94 \\
(0.8)\end{array}$ \\
\hline $\ln w_{i, t-1}^{F} * D_{i, t}$ & & & $\begin{array}{c}0.33^{* * *} \\
(2.9)\end{array}$ & $\begin{array}{c}0.24^{* *} \\
(1.9)\end{array}$ & $\begin{array}{r}0.19^{*} \\
(1.8)\end{array}$ & $\begin{array}{l}0.15 \\
(1.4)\end{array}$ & $\begin{array}{c}0.19^{* *} \\
(2.0)\end{array}$ & $\begin{array}{c}0.20^{* *} \\
(2.0)\end{array}$ & $\begin{array}{c}0.20^{* *} \\
(2.1)\end{array}$ & $\begin{array}{c}0.20^{* *} \\
(2.4)\end{array}$ \\
\hline n. Obs. & 1970 & 1335 & 1335 & 1366 & 1335 & 1366 & 1335 & 1366 & 1335 & 1366 \\
\hline$F$ test & $\begin{array}{c}50 \\
(0.0)\end{array}$ & $\begin{array}{c}34 \\
(0.0)\end{array}$ & $\begin{array}{c}20 \\
(0.0)\end{array}$ & $\begin{array}{c}14 \\
(0.0)\end{array}$ & $\begin{array}{c}15 \\
(0.0)\end{array}$ & $\begin{array}{c}18 \\
(0.0)\end{array}$ & $\begin{array}{c}14 \\
(0.0)\end{array}$ & $\begin{array}{c}15 \\
(0.0)\end{array}$ & $\begin{array}{c}14 \\
(0.0)\end{array}$ & $\begin{array}{c}18 \\
(0.0)\end{array}$ \\
\hline Hansen test & $\begin{array}{l}122 \\
(85)\end{array}$ & $\begin{array}{c}61 \\
(57)\end{array}$ & $\begin{array}{c}115 \\
(117)\end{array}$ & $\begin{array}{c}126 \\
(117)\end{array}$ & $\begin{array}{c}113 \\
(117)\end{array}$ & $\begin{array}{c}103 \\
(117)\end{array}$ & $\begin{array}{c}112 \\
(117)\end{array}$ & $\begin{array}{c}114 \\
(117)\end{array}$ & $\begin{array}{c}112 \\
(117)\end{array}$ & $\begin{array}{c}104 \\
(117)\end{array}$ \\
\hline $\mathrm{p}$-value & 0.010 & 0.337 & 0.541 & 0.263 & 0.581 & 0.820 & 0.611 & 0.544 & 0.626 & 0.792 \\
\hline \multirow{2}{*}{\multicolumn{11}{|c|}{ P-value of $\mathrm{H}_{0}: \pi_{4}=0$ for the $D_{i, t}=1$ group }} \\
\hline & & & & & & & 0.07 & 0.01 & 0.05 & 0.00 \\
\hline
\end{tabular}

\footnotetext{
* Significant at the $10 \%$ level; ${ }^{* *}$ significant at the $5 \%$ level; ${ }^{* * *}$ significant at the $1 \%$ level. The coefficients are estimated with a two step robust System GMM estimator (Blundell and Bond, 1998). The t-statistic is reported in parentheses. The finite-sample correction to the two-step covariance matrix is derived by Windmeijer (2005). We use the command Xtabond2 in the software package Stata. The variables are described in appendix 5. The smallest $1 \%$ and largest $1 \%$ of the first differences of the regressors and of the dependent variable are eliminated as outliers. Year dummy variables are entered as strictly exogenous regressors.

Instruments for the equation in levels are t- 1 to $t-3$ first differences of the regressors and $t-2$ to $t-3$ the first differences of the dependent variable. Instruments for the equation in first differences are t-3 levels of the regressors and of the dependent variable. The F. test reports the test of joint significance of all estimated coefficients. The Hansen test of overidentifying restrictions is reported. This test is robust to autocorrelation and heteroskedasticity of unknown form. In columns "(1)" financial wealth is defined by equation (45). In columns "(2)" financial wealth is defined by equation (48). The p-value in the last row is the probability to reject $H_{0}$ when it is true.
} 
Table VIII: Structural parameters.

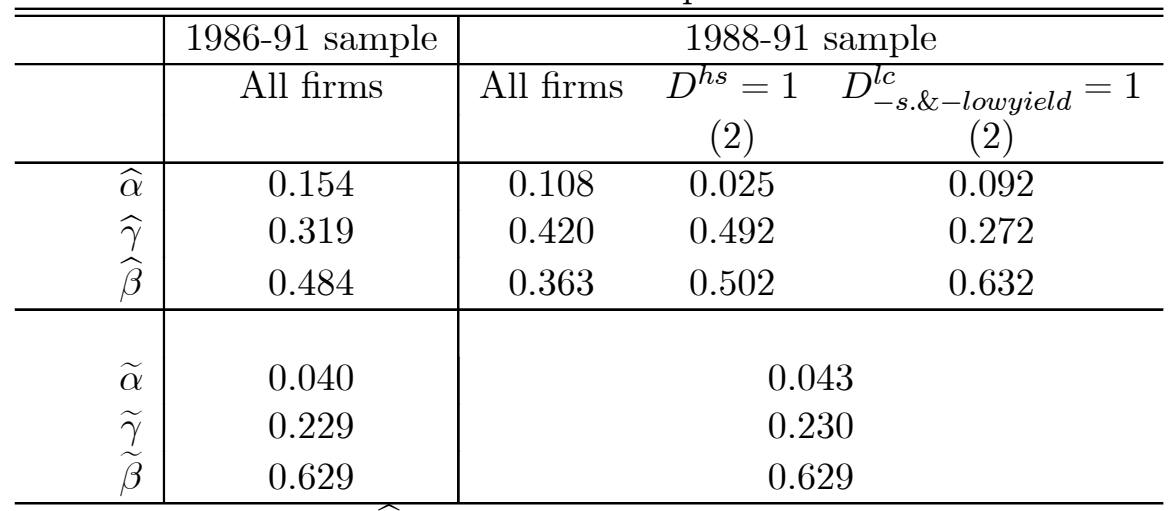

The estimates $\widehat{\alpha}, \widehat{\gamma}$ and $\widehat{\beta}$ are derived from the corresponding columns of table $\mathrm{V}$, using the restrictions in equation (44). $\widetilde{\gamma}=$ average of (labor cost/output), $\widetilde{\beta}=$ average of (materials cost/output), $\widetilde{\alpha}=$ average of (user cost of fixed capital/output). The user cost of fixed capital is computed by assuming that $\delta=0.1$. 
Table IX: Financing constraints test, direct and indirect criteria, 1986-91 sample.

\begin{tabular}{|c|c|c|c|c|c|c|}
\hline \multicolumn{7}{|c|}{$\begin{array}{c}\text { Regression: } \\
\ln l_{i, t}=\pi_{0}+a_{i}+d_{t}+\pi_{1} \ln \theta_{i, t-1}+\pi_{2} \ln k_{i, t-1}+\pi_{3} \ln n_{i, t}+\pi_{4} \ln w_{i, t-1}^{F}+\varepsilon_{i, t} \\
\end{array}$} \\
\hline & \multicolumn{6}{|c|}{ Indirect Criteria } \\
\hline & \multicolumn{2}{|c|}{$D^{a g e}$} & \multicolumn{2}{|c|}{$D^{\text {divpol }}$} & \multicolumn{2}{|c|}{$D^{\text {size }}$} \\
\hline & (1) & (2) & (1) & $(2)$ & (1) & (2) \\
\hline $\ln k_{i, t-1}$ & $\begin{array}{c}0.33^{* * *} \\
(3.4)\end{array}$ & $\begin{array}{c}0.28^{* *} \\
(2.2)\end{array}$ & $\begin{array}{c}0.35^{* *} \\
(3.3)\end{array}$ & $\begin{array}{c}0.31^{* *} \\
(2.3)\end{array}$ & $\begin{array}{c}0.36^{* *} \\
(3.1)\end{array}$ & $\begin{array}{c}0.29^{* *} \\
(2.0)\end{array}$ \\
\hline $\ln n_{i, t}$ & $\begin{array}{c}0.59^{* * *} \\
(4.7)\end{array}$ & $\begin{array}{c}0.56^{* * *} \\
(3.6)\end{array}$ & $\begin{array}{c}0.42^{* *} \\
(2.4)\end{array}$ & $\begin{array}{l}0.29^{*} \\
(1.7)\end{array}$ & $\begin{array}{c}0.46^{* * *} \\
(2.6)\end{array}$ & $\begin{array}{c}0.53^{* * *} \\
(2.7)\end{array}$ \\
\hline $\ln \theta_{i, t-1}$ & $\begin{array}{l}1.99^{*} \\
(1.7)\end{array}$ & $\begin{array}{l}2.12^{*} \\
(1.6)\end{array}$ & $\begin{array}{c}4.02^{* * *} \\
(2.9)\end{array}$ & $\begin{array}{c}4.50^{* * *} \\
(2.6)\end{array}$ & $\begin{array}{c}3.06^{* * *} \\
(2.5)\end{array}$ & $\begin{array}{c}3.27^{* *} \\
(2.4)\end{array}$ \\
\hline $\ln w_{i, t-1}^{F}$ & $\begin{array}{l}0.01 \\
(0.2)\end{array}$ & $\begin{array}{l}-0.08 \\
(-1.5)\end{array}$ & $\begin{array}{l}-0.01 \\
(-0.1)\end{array}$ & $\begin{array}{l}-0.09 \\
(-1.3)\end{array}$ & $\begin{array}{l}0.01 \\
(0.2)\end{array}$ & $\begin{array}{l}-0.03 \\
(-0.6)\end{array}$ \\
\hline $\ln k_{i, t-1} * D_{i, t}$ & $\begin{array}{c}-0.49^{* *} \\
(-2.3)\end{array}$ & $\begin{array}{c}-0.34^{*} \\
(-1.7)\end{array}$ & $\begin{array}{l}-0.21 \\
(-1.3)\end{array}$ & $\begin{array}{l}-0.23 \\
(-1.3)\end{array}$ & $\begin{array}{l}-0.27 \\
(-1.5)\end{array}$ & $\begin{array}{l}-0.32 \\
(-1.4)\end{array}$ \\
\hline $\ln n_{i, t} * D_{i, t}$ & $\begin{array}{l}0.04 \\
(0.2)\end{array}$ & $\begin{array}{l}-0.09 \\
(-0.5)\end{array}$ & $\begin{array}{c}0.36^{*} \\
(1.6)\end{array}$ & $\begin{array}{c}0.55^{* *} \\
(2.5)\end{array}$ & $\begin{array}{l}0.01 \\
(0.1)\end{array}$ & $\begin{array}{l}-0.43 \\
(-1.4)\end{array}$ \\
\hline $\ln \theta_{i, t-1} * D_{i, t}$ & $\begin{array}{l}-0.62 \\
(-0.2)\end{array}$ & $\begin{array}{l}0.56 \\
(0.2)\end{array}$ & $\begin{array}{c}-4.69^{* *} \\
(-2.4)\end{array}$ & $\begin{array}{c}-4.88^{* *} \\
(-2.2)\end{array}$ & $\begin{array}{l}-1.66 \\
(-0.7)\end{array}$ & $\begin{array}{l}-1.47 \\
(-0.6)\end{array}$ \\
\hline $\ln w_{i, t-1}^{F}{ }^{*} D_{i, t}$ & $\begin{array}{c}0.32^{* *} \\
(2.2)\end{array}$ & $\begin{array}{c}0.41^{* * *} \\
(3.5)\end{array}$ & $\begin{array}{l}0.09 \\
(1.1)\end{array}$ & $\begin{array}{c}0.29^{*} \\
(1.7)\end{array}$ & $\begin{array}{c}0.24^{* *} \\
(2.3)\end{array}$ & $\begin{array}{c}0.26^{* *} \\
(2.1)\end{array}$ \\
\hline n. Obs. & 1970 & 2017 & 1970 & 2017 & 1970 & 2017 \\
\hline$F$ test & $\begin{array}{c}24 \\
(0.0) \\
\end{array}$ & $\begin{array}{c}16 \\
(0.0) \\
\end{array}$ & $\begin{array}{c}24 \\
(0.0) \\
\end{array}$ & $\begin{array}{c}23 \\
(0.0) \\
\end{array}$ & $\begin{array}{c}35 \\
(0.0) \\
\end{array}$ & $\begin{array}{c}31 \\
(0.0) \\
\end{array}$ \\
\hline Hansen t. & $\begin{array}{c}165 \\
(175) \\
0.687\end{array}$ & $\begin{array}{c}229 \\
(175) \\
0.004\end{array}$ & $\begin{array}{c}198 \\
(175) \\
0.105\end{array}$ & $\begin{array}{c}245 \\
(175) \\
0.000\end{array}$ & $\begin{array}{c}186 \\
(175) \\
0.269\end{array}$ & $\begin{array}{c}239 \\
(175) \\
0.001\end{array}$ \\
\hline \multicolumn{7}{|c|}{ P-value of $\mathrm{H}_{0}: \pi_{4}=0$ for the $D_{i, t}=1$ group } \\
\hline & 0.02 & 0.002 & 0.15 & 0.21 & 0.01 & 0.040 \\
\hline
\end{tabular}

* Significant at the $10 \%$ level; ${ }^{* *}$ significant at the $5 \%$ level; ${ }^{* * *}$ significant at the $1 \%$ level. The coefficients are estimated with a two step robust System GMM estimator (Blundell and Bond, 1998). The t-statistic is reported in parentheses. See the footnote to table VII for details. 
Table X: Financing constraints test: direct revelation criteria and the 1988-91 sample. Alternative definition of wealth.

\begin{tabular}{|c|c|c|c|c|c|}
\hline \multicolumn{6}{|c|}{$\begin{array}{c}\text { Regression: } \ln l_{i, t}= \\
\pi_{0}+a_{i}+d_{t}+\pi_{1} \ln \theta_{i, t-1}+\pi_{2} \ln k_{i, t-1}+\pi_{3} \ln n_{i, t}+\pi_{4} \ln \widetilde{w}_{i, t-1}^{F}+\varepsilon_{i, t}\end{array}$} \\
\hline & $\overline{D^{h s}}$ & $\overline{\overline{D^{l c}}}$ & $\overline{\overline{D^{a g e}}}$ & 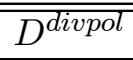 & 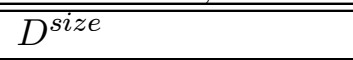 \\
\hline $\ln k_{i, t-1}$ & $\begin{array}{l}-0.01 \\
(-0.1)\end{array}$ & $\begin{array}{l}0.16 \\
(1.4)\end{array}$ & $\begin{array}{c}0.28^{* * *} \\
(2.6)\end{array}$ & $\begin{array}{c}0.23^{* *} \\
(1.9)\end{array}$ & $\begin{array}{l}0.23^{*} \\
(1.8)\end{array}$ \\
\hline $\ln n_{i, t}$ & $\begin{array}{c}1.06^{* * *} \\
(6.4)\end{array}$ & $\begin{array}{c}0.84^{* * *} \\
(5.6)\end{array}$ & $\begin{array}{c}0.64^{* * *} \\
(4.6)\end{array}$ & $\begin{array}{c}0.58^{* * *} \\
(2.9)\end{array}$ & $\begin{array}{l}0.77^{* * *} \\
(4.9)\end{array}$ \\
\hline $\ln \theta_{i, t-1}$ & $\begin{array}{l}1.27 \\
(1.1)\end{array}$ & $\begin{array}{l}1.48 \\
(1.2)\end{array}$ & $\begin{array}{l}0.77 \\
(0.5)\end{array}$ & $\begin{array}{l}3.23 \\
(1.5)\end{array}$ & $\begin{array}{l}3.03^{* *} \\
(1.9)\end{array}$ \\
\hline $\ln \widetilde{w}_{i, t-1}^{F}$ & $\begin{array}{l}-0.02 \\
(-0.8)\end{array}$ & $\begin{array}{l}-0.04 \\
(-1.3)\end{array}$ & $\begin{array}{l}-0.05 \\
(-1.6)\end{array}$ & $\begin{array}{l}-0.07 \\
(-1.4)\end{array}$ & $\begin{array}{l}-0.05 \\
(-1.5)\end{array}$ \\
\hline $\ln k_{i, t-1} * D_{i, t}$ & $\begin{array}{l}0.37 \\
(1.4)\end{array}$ & $\begin{array}{l}0.21 \\
(1.0)\end{array}$ & $\begin{array}{c}-0.25^{*} \\
(-1.7)\end{array}$ & $\begin{array}{l}-0.07 \\
(-0.4)\end{array}$ & $\begin{array}{l}-0.20 \\
(-1.1)\end{array}$ \\
\hline $\ln n_{i, t} * D_{i, t}$ & $\begin{array}{c}-0.54^{* *} \\
(-1.9)\end{array}$ & $\begin{array}{l}-0.25 \\
(-1.3)\end{array}$ & $\begin{array}{l}0.11 \\
(0.8)\end{array}$ & $\begin{array}{l}0.11 \\
(0.5)\end{array}$ & $\begin{array}{c}-0.59^{*} \\
(-1.9)\end{array}$ \\
\hline $\ln \theta_{i, t-1} * D_{i, t}$ & $\begin{array}{l}-2.83 \\
(-0.5)\end{array}$ & $\begin{array}{l}4.32 \\
(0.6)\end{array}$ & $\begin{array}{l}1.92 \\
(0.7)\end{array}$ & $\begin{array}{l}-4.68 \\
(-1.6)\end{array}$ & $\begin{array}{l}-6.64^{* *} \\
(-2.0)\end{array}$ \\
\hline $\ln \widetilde{w}_{i, t-1}^{F} * D_{i, t}$ & $\begin{array}{c}0.18^{*} \\
(1.8)\end{array}$ & $\begin{array}{l}0.02 \\
(0.2)\end{array}$ & $\begin{array}{l}0.12 \\
(1.5)\end{array}$ & $\begin{array}{l}0.16^{*} \\
(1.8)\end{array}$ & $\begin{array}{l}0.28^{* * *} \\
(3.0)\end{array}$ \\
\hline n. Obs. & 1115 & 1115 & 1628 & 1628 & 1628 \\
\hline$F$ test & $\begin{array}{c}17 \\
(0.0)\end{array}$ & $\begin{array}{c}21 \\
(0.0)\end{array}$ & $\begin{array}{c}22 \\
(0.0)\end{array}$ & $\begin{array}{c}27 \\
(0.0)\end{array}$ & $\begin{array}{l}29 \\
(0.0) \\
\end{array}$ \\
\hline Hansen test & $\begin{array}{c}114 \\
(117)\end{array}$ & $\begin{array}{c}99 \\
(117)\end{array}$ & $\begin{array}{c}193 \\
(175)\end{array}$ & $\begin{array}{c}237 \\
(175)\end{array}$ & $\begin{array}{l}215 \\
(175)\end{array}$ \\
\hline $\mathrm{p}$-value & 0.545 & 0.878 & 0.159 & 0.001 & 0.021 \\
\hline
\end{tabular}

* Significant at the $10 \%$ level; ** significant at the $5 \%$ level; *** significant at the $1 \%$ level. $\widetilde{w}_{i, t}^{F}$ it is equal to $w_{i, t}^{F}$ as defined in equation (45) net of finished goods inventories. The coefficients are estimated with a two step robust System GMM estimator (Blundell and Bond, 1998). The t-statistic is reported in parentheses. See the footnote to table VII for details. 
Table XI: Financing constraints test: estimation of the sample based on the 1998 and 2001 Surveys.

\begin{tabular}{|c|c|c|c|c|c|c|c|c|}
\hline \multicolumn{9}{|c|}{$\begin{array}{l}\text { Regression: } \\
\quad \theta_{i, t-1}+\pi_{2} \ln k_{i, t-1}+\pi_{3} \ln n_{i, t}+\pi_{4} \ln w_{i, t-1}^{F}+\varepsilon_{i, t}\end{array}$} \\
\hline & \multicolumn{2}{|c|}{ D } & \multicolumn{2}{|c|}{ D } & \multicolumn{2}{|c|}{$\overline{D^{a g e}}$} & \multicolumn{2}{|c|}{$D^{\text {size }}$} \\
\hline $\ln k_{i, t-1}$ & $\begin{array}{c}0.19^{* * *} \\
(3.4)\end{array}$ & $\begin{array}{c}0.22^{* * *} \\
(4.4)\end{array}$ & $\begin{array}{c}0.20^{* * *} \\
(3.9)\end{array}$ & $\begin{array}{c}0.21^{* * *} \\
(4.6)\end{array}$ & $\begin{array}{c}0.21^{* * *} \\
(3.6)\end{array}$ & $\begin{array}{c}0.22^{* * *} \\
(4.1)\end{array}$ & $\begin{array}{c}0.20^{* * *} \\
(3.6)\end{array}$ & $\begin{array}{c}0.20^{* * *} \\
(4.0)\end{array}$ \\
\hline $\ln n_{i, t}$ & $\begin{array}{l}0.75^{* * *} \\
(9.7)\end{array}$ & $\begin{array}{c}0.80 * * * \\
(10.9)\end{array}$ & $\begin{array}{c}0.73^{* * *} \\
(10.2)\end{array}$ & $\begin{array}{c}0.79^{* * *} \\
(11.0)\end{array}$ & $\begin{array}{c}0.68^{* * *} \\
(8.9)\end{array}$ & $\begin{array}{c}0.68^{* * *} \\
(9.5)\end{array}$ & $\begin{array}{c}0.72^{* * *} \\
(8.9)\end{array}$ & $\begin{array}{c}0.72^{* * *} \\
(8.9)\end{array}$ \\
\hline $\ln \theta_{i, t-1}$ & $\begin{array}{c}1.40^{* * *} \\
(3.6)\end{array}$ & $\begin{array}{c}1.43^{* * *} \\
(3.6)\end{array}$ & $\begin{array}{c}1.45^{* * *} \\
(3.6)\end{array}$ & $\begin{array}{c}1.26^{* * *} \\
(3.1)\end{array}$ & $\begin{array}{c}1.60^{* * *} \\
(4.0)\end{array}$ & $\begin{array}{c}1.51^{* * *} \\
(4.1)\end{array}$ & $\begin{array}{c}1.47^{* * *} \\
(4.0)\end{array}$ & $\begin{array}{c}1.26^{* * *} \\
(3.6)\end{array}$ \\
\hline $\ln w_{i, t-1}^{F}$ & $\begin{array}{l}-0.04 \\
(-1.4)\end{array}$ & $\begin{array}{l}-0.05 \\
(-1.5)\end{array}$ & $\begin{array}{l}-0.01 \\
(-0.3)\end{array}$ & $\begin{array}{l}-0.03 \\
(-1.2)\end{array}$ & $\begin{array}{l}-0.03 \\
(-0.9)\end{array}$ & $\begin{array}{l}-0.03 \\
(-1.1)\end{array}$ & $\begin{array}{l}-0.02 \\
(-0.6)\end{array}$ & $\begin{array}{l}-0.05 \\
(-1.4)\end{array}$ \\
\hline $\ln k_{i, t-1} * D_{i, t}$ & $\begin{array}{l}-0.08 \\
(-0.8)\end{array}$ & $\begin{array}{l}-0.09 \\
(-0.8)\end{array}$ & $\begin{array}{l}-0.06 \\
(-0.4)\end{array}$ & $\begin{array}{l}-0.12 \\
(-0.6)\end{array}$ & $\begin{array}{l}-0.08 \\
(-0.9)\end{array}$ & $\begin{array}{l}-0.01 \\
(-0.1)\end{array}$ & $\begin{array}{l}0.00 \\
(0.0)\end{array}$ & $\begin{array}{l}0.03 \\
(0.3)\end{array}$ \\
\hline $\ln n_{i, t} * D_{i, t}$ & $\begin{array}{l}-0.07 \\
(-0.6)\end{array}$ & $\begin{array}{l}-0.11 \\
(-0.7)\end{array}$ & $\begin{array}{l}-0.06 \\
(-0.3)\end{array}$ & $\begin{array}{l}-0.15 \\
(-0.7)\end{array}$ & $\begin{array}{l}0.06 \\
(0.6)\end{array}$ & $\begin{array}{l}-0.03 \\
(-0.3)\end{array}$ & $\begin{array}{c}-0.34^{*} \\
(-1.8)\end{array}$ & $\begin{array}{c}-0.25^{* *} \\
(-2.0)\end{array}$ \\
\hline $\ln \theta_{i, t-1} * D_{i, t}$ & $\begin{array}{l}-1.22 \\
(-1.4)\end{array}$ & $\begin{array}{l}-1.37^{*} \\
(-1.6)\end{array}$ & $\begin{array}{l}-0.81 \\
(-0.9)\end{array}$ & $\begin{array}{l}-1.02 \\
(-1.2)\end{array}$ & $\begin{array}{l}-1.89 \\
(-1.5)\end{array}$ & $\begin{array}{c}-2.23^{* *} \\
(-2.1)\end{array}$ & $\begin{array}{l}-0.82 \\
(-0.7)\end{array}$ & $\begin{array}{l}-0.60 \\
(-0.5)\end{array}$ \\
\hline $\ln w_{i, t-1}^{F} * D_{i, t}$ & $\begin{array}{c}0.15^{* * *} \\
(2.7) \\
\end{array}$ & $\begin{array}{c}0.18^{* * *} \\
(2.8)\end{array}$ & $\begin{array}{c}0.14^{*} \\
(1.6)\end{array}$ & $\begin{array}{c}0.26^{* * *} \\
(2.8) \\
\end{array}$ & $\begin{array}{l}0.01 \\
(0.2) \\
\end{array}$ & $\begin{array}{l}0.05 \\
(0.7) \\
\end{array}$ & $\begin{array}{l}0.07 \\
(0.8) \\
\end{array}$ & $\begin{array}{c}0.16^{* *} \\
(2.5)\end{array}$ \\
\hline n. Obs. & 4656 & 5266 & 4656 & 5266 & 4656 & 5266 & 4656 & 5266 \\
\hline$F$ test & $\begin{array}{c}24 \\
(0.0)\end{array}$ & $\begin{array}{c}36 \\
(0.0)\end{array}$ & $\begin{array}{c}34 \\
(0.0)\end{array}$ & $\begin{array}{c}40 \\
(0.0)\end{array}$ & $\begin{array}{c}31 \\
(0.0)\end{array}$ & $\begin{array}{c}26 \\
(0.0)\end{array}$ & $\begin{array}{c}39 \\
(0.0)\end{array}$ & $\begin{array}{c}40 \\
(0.0)\end{array}$ \\
\hline Hansen test & $\begin{array}{c}289 \\
(254)\end{array}$ & $\begin{array}{c}285 \\
(254)\end{array}$ & $\begin{array}{c}206 \\
(254)\end{array}$ & $\begin{array}{c}219 \\
(254)\end{array}$ & $\begin{array}{c}267 \\
(254)\end{array}$ & $\begin{array}{c}287 \\
(254)\end{array}$ & $\begin{array}{c}258 \\
(254)\end{array}$ & $\begin{array}{c}278 \\
(254)\end{array}$ \\
\hline p-value & 0.089 & 0.086 & 0.988 & 0.945 & 0.248 & 0.076 & 0.411 & 0.141 \\
\hline \multicolumn{9}{|c|}{ P-value of $\mathrm{H}_{0}: \pi_{4}=0$ for the $D_{i, t}=1$ group } \\
\hline & 0.019 & 0.019 & 0.123 & 0.015 & 0.750 & 0.076 & 0.497 & 0.044 \\
\hline
\end{tabular}

* Significant at the $10 \%$ level; ${ }^{* *}$ significant at the $5 \%$ level; ${ }^{* * *}$ significant at the $1 \%$ level. The coefficients are estimated with a two step robust System GMM estimator (Blundell and Bond, 1998). The t-statistic is reported in parentheses. See the footnote to table VII for details.

Table XII: Summary statistics of the variables used to estimate the production function.

\begin{tabular}{ccccc}
\hline \hline Variable & Mean & St.Dev & Min & Max \\
\hline \hline$y_{i, t}$ & 33.105 & 68.002 & 1.095 & 1162.078 \\
$l_{i, t}$ & 19.582 & 51.121 & 0.093 & 1200.405 \\
$n_{i, t}$ & 11.303 & 19.475 & 0.343 & 235.296 \\
$k_{i, t}$ & 8.179 & 18.454 & 0.067 & 259.543 \\
\hline
\end{tabular}

Values are in billions of Italian Lire, 1982 prices. 1 Billion lire was equal to 0.71 million US $\$$ at the 1982 exchange rate. $y_{i, t}=$ total revenues; $k_{i, t}=$ replacement value of the plant, equipment and other intangible fixed assets; $l_{i, t}=$ usage of materials; $n_{i, t}=$ labor cost. 
Table XIII: Composition of the groups for which the production function is separately estimated.

\begin{tabular}{ll}
\hline \hline Two Digits ISTAT* Sectors & Number of firms \\
\hline \hline Group 1: Industrial Machinery & 78 \\
Group 2: Electronic Machinery, Precision Instruments & 49 \\
Group 3: Textiles, Shoes and Clothes, Wood Furniture & 117 \\
Group 4: Chemicals, Rubber and Plastics & 63 \\
Group 5: Metallic Products & 80 \\
Group 6: Food, Sugar and Tobaccos, Paper and Printing & 66 \\
Group 7: Non-metallic Minerals, Other Manufacturing & 108 \\
\hline * Italian National Statistic Institute &
\end{tabular}

Table XIV: Production function estimation results.

\begin{tabular}{c|cccccccc}
\hline \hline & All Firms & Group 1 & Group 2 & Group 3 & Group 4 & Group 5 & Group6 & Group 7 \\
\hline \hline$\widehat{\alpha}$ & 0.111 & 0.105 & 0.062 & 0.114 & 0.081 & 0.038 & 0.040 & 0.198 \\
& $(0.02)$ & $(0.02)$ & $(0.015)$ & $(0.03)$ & $(0.02)$ & $(0.022)$ & $(0.01)$ & $(0.02)$ \\
$\widehat{\beta}$ & 0.389 & 0.377 & 0.289 & 0.424 & 0.454 & 0.393 & 0.562 & 0.406 \\
& $(0.02)$ & $(0.01)$ & $(0.013)$ & $(0.03)$ & $(0.01)$ & $(0.017)$ & $(0.01)$ & $(0.024)$ \\
$\widehat{\gamma}$ & 0.441 & 0.494 & 0.468 & 0.348 & 0.193 & 0.491 & 0.350 & 0.401 \\
& $(0.03)$ & $(0.02)$ & $(0.023)$ & $(0.04)$ & $(0.01)$ & $(0.034)$ & $(0.01)$ & $(0.05)$ \\
\hline Sargan T. & 65.50 & 38.90 & 25.78 & 39.87 & 39.71 & 38.20 & 45.18 & 33.64 \\
D.f. & 37 & 37 & $27^{* *}$ & 37 & 37 & 37 & $36^{*}$ & $36^{*}$ \\
P-value & 0.00 & 0.38 & 0.53 & 0.34 & 0.35 & 0.40 & 0.14 & 0.58 \\
\hline$\chi^{2 * * *}$ & & 29.7 & 41.7 & 814.6 & 217.2 & 9.61 & 11.35 & 0.01 \\
p-value & & 0.00 & 0.00 & 0.00 & 0.00 & 0.00 & 0.00 & 0.91 \\
\hline n. firms & 561 & 78 & 49 & 117 & 63 & 80 & 66 & 108 \\
n. obs. & 4488 & 624 & 392 & 936 & 504 & 640 & 528 & 864 \\
\hline
\end{tabular}

* One coefficient relative to a two-digit sector dummy variable is estimated here. ** Only $t-1$ instruments used for the estimation of this group, due to the reduced number of observations. *** Wald test of the following restriction: $\alpha+\beta+\gamma=1$. Standard deviations are in parentheses. $\widehat{\alpha}=$ estimated elasticity of output to fixed capital. $\widehat{\beta}=$ estimated elasticity of output to variable capital. $\widehat{\gamma}=$ estimated elasticity of output to labor. Sargan test is a test of the overidentifying restrictions. 
Table XV: Test of the validity of the instruments.

\begin{tabular}{|c|c|c|c|}
\hline \multicolumn{4}{|c|}{$\begin{array}{c}\text { Regression: } \ln l_{i, t}= \\
\mathrm{n} \theta_{i, t-1}+\pi_{2} \ln k_{i, t-1}+\pi_{3} \ln n_{i, t}+\pi_{4} \ln \widetilde{w}_{i, t-1}^{F}+\varepsilon_{i, t} \\
\end{array}$} \\
\hline & $\begin{array}{l}\text { t- } 1 \text { to t- } 3 \text { first } \\
\text { differences }{ }^{1} \text { as } \\
\text { instruments of } \\
\text { the levels eq. }\end{array}$ & $\begin{array}{l}\text { t- } 2 \text { to t- } 3 \text { levels } \\
\text { as instruments } \\
\text { of the equation in } \\
\text { first differences }\end{array}$ & $\begin{array}{l}\text { t- } 3 \text { to t- } 4 \text { levels } \\
\text { as instruments } \\
\text { of the equation } \\
\text { in first differences }\end{array}$ \\
\hline \multicolumn{4}{|c|}{ Hansen $J$ statistic (p-value) - cross sectional equations } \\
\hline 1986 & 0.34 & 0.67 & \\
\hline 1987 & 0.46 & 0.03 & 0.87 \\
\hline 1988 & 0.81 & 0.53 & 0.89 \\
\hline 1989 & 0.51 & 0.58 & 0.66 \\
\hline 1990 & 0.27 & 0.51 & 0.67 \\
\hline 1991 & 0.93 & 0.03 & 0.11 \\
\hline \multicolumn{4}{|c|}{ First stage regressions statistics } \\
\hline $\ln k_{i, t-1}:$ Shea's partial $R^{2}$ & 0.01 & 0.13 & 0.07 \\
\hline $\ln k_{i, t-1}:$ F stat. (p-val.) & $1(0.60)$ & $24(0.000)$ & $10(0.000)$ \\
\hline $\ln n_{i, t}:$ Shea's partial $R^{2}$ & 0.025 & 0.05 & 0.03 \\
\hline $\ln n_{i, t}:$ F stat. (p-value) & $1.1(0.37)$ & $10(0.000)$ & $5.4(0.000)$ \\
\hline $\ln w_{i, t}^{F}:$ Shea's partial $R^{2}$ & 0.16 & 0.16 & 0.01 \\
\hline $\ln w_{i, t}^{F}:$ F stat. (p-value) & $5.2(0.000)$ & $20(0.000)$ & $2.3(0.013)$ \\
\hline $\ln \theta_{i, t}:$ Shea's part. $R^{2}$ & 0.44 & 0.31 & 0.05 \\
\hline $\ln \theta_{i, t}:$ F stat. (p-val.) & $60.4(0.000)$ & $44(0.000)$ & $12(0.00)$ \\
\hline
\end{tabular}

